\title{
Toxicity of Nanoparticles in Biomedical Application: Nanotoxicology
}

\author{
Chukwuebuka Egbuna (iD, ${ }^{1,2,3}$ Vijaykumar K. Parmar, ${ }^{4}$ Jaison Jeevanandam, \\ Shahira M. Ezzat, ${ }^{6,7}$ Kingsley C. Patrick-Iwuanyanwu, ${ }^{1,2}$ Charles Oluwaseun Adetunji, ${ }^{8}$ \\ Johra Khan, ${ }^{9,10}$ Eugene N. Onyeike, ${ }^{1,2}$ Chukwuemelie Zedech Uche, ${ }^{11}$ \\ Muhammad Akram, ${ }^{12}$ Mervat S. Ibrahim, ${ }^{13}$ Nihal M. El Mahdy, ${ }^{13}$ \\ Chinaza Godswill Awuchi, ${ }^{14}$ Kaliyaperumal Saravanan ${ }^{(D)},{ }^{15}$ Habibu Tijjani, ${ }^{16}$ \\ Uchenna Estella Odoh, ${ }^{17}$ Mohammed Messaoudi $\mathbb{D},{ }^{18,19}$ Jonathan C. Ifemeje, ${ }^{3}$ \\ Michael C. Olisah, ${ }^{20}$ Nebechi Jane Ezeofor, ${ }^{21}$ Chukwudi Jude Chikwendu, ${ }^{3}$ \\ and Chinwe Gloria Ibeabuchi ${ }^{1,2}$
}

\footnotetext{
${ }^{1}$ Africa Centre of Excellence in Public Health and Toxicological Research (ACE-PUTOR),

Nutritional Biochemistry and Toxicology Unit, University of Port-Harcourt, Port Harcourt, Rivers State, Nigeria

${ }^{2}$ Department of Biochemistry, Faculty of Science, University of Port Harcourt, East-West Road, P.M.B 5323, Port Harcourt, Rivers State, Nigeria

${ }^{3}$ Department of Biochemistry, Faculty of Natural Sciences, Chukwuemeka Odumegwu Ojukwu University, Uli, Anambra State 431124, Nigeria

${ }^{4}$ Department of Pharmaceutical Sciences, Sardar Patel University, Vallabh Vidyanagar - 388 120, Gujarat, India

${ }^{5}$ CQM-Centro de Química da Madeira, MMRG, Universidade da Madeira, Campus da Penteada, 9020-105 Funchal, Portugal

${ }^{6}$ Department of Pharmacognosy, Faculty of Pharmacy, Cairo University, Kasr El Ainy Street, 11562 Cairo, Egypt

${ }^{7}$ Department of Pharmacognosy, Faculty of Pharmacy, October University for Modern Sciences and Arts (MSA), 6th of October 12566, Egypt

${ }^{8}$ Applied Microbiology, Biotechnology and Nanotechnology Laboratory, Department of Microbiology, Edo University Iyamho, PMB 04 Auchi, Edo State, Nigeria

${ }^{9}$ Department of Medical Laboratory Sciences, College of Applied Medical Sciences, Majmaah University, Majmaah 11952, Saudi Arabia

${ }^{10}$ Health and Basic Sciences Research Center, Majmaah University, Majmaah 11952, Saudi Arabia

${ }^{11}$ Department of Medical Biochemistry and Molecular Biology, Faculty of Basic Medical Sciences, University of Nigeria, Enugu Campus, Nsukka, Nigeria

${ }^{12}$ Department of Eastern Medicines, Government College University, Faisalabad, Pakistan

${ }^{13}$ Department of Pharmaceutics and Industrial Pharmacy, Faculty of Pharmacy, October University for Modern Sciences and Arts (MSA), 6th of October 12566, Egypt

${ }^{14}$ School of Natural and Applied Sciences, Kampala International University, Kampala, Uganda

${ }^{15}$ PG and Research Department of Zoology, Nehru Memorial College (Autonomous), Puthanampatti-621 007, Bharathidasan University, Tiruchirappalli, Tamil Nadu, India

${ }^{16}$ Department of Biochemistry, Natural Product Research Laboratory, Bauchi State University, Gadau, Nigeria

${ }^{17}$ Department of Pharmacognosy and Environmental Medicines, Faculty of Pharmaceutical Sciences, University of Nigeria, Nsukka, Nigeria

${ }^{18}$ Nuclear Research Centre of Birine, Ain Oussera, P.O. Box 180, Djelfa 17200, Algeria

${ }^{19}$ Chemistry Department, University of Hamma Lakhdar, B.P. 789, El-Oued 39000, Algeria
} 
${ }^{20}$ Department of Medical Biochemistry, Faculty of Basic Medical Sciences, Chukwuemeka Odumegwu Ojukwu University, Uli,
Anambra State 431124, Nigeria
${ }^{21}$ Department of Food Technology, School of Applied Science and Technology, Federal Polytechnic, Oko, Anambra State, Nigeria

Correspondence should be addressed to Chukwuebuka Egbuna; egbuna.chukwuebuka@uniport.edu.ng

Received 7 March 2021; Accepted 15 July 2021; Published 30 July 2021

Academic Editor: You-Cheng Hseu

Copyright ( $\odot 2021$ Chukwuebuka Egbuna et al. This is an open access article distributed under the Creative Commons Attribution License, which permits unrestricted use, distribution, and reproduction in any medium, provided the original work is properly cited.

Nanoparticles are of great importance in development and research because of their application in industries and biomedicine. The development of nanoparticles requires proper knowledge of their fabrication, interaction, release, distribution, target, compatibility, and functions. This review presents a comprehensive update on nanoparticles' toxic effects, the factors underlying their toxicity, and the mechanisms by which toxicity is induced. Recent studies have found that nanoparticles may cause serious health effects when exposed to the body through ingestion, inhalation, and skin contact without caution. The extent to which toxicity is induced depends on some properties, including the nature and size of the nanoparticle, the surface area, shape, aspect ratio, surface coating, crystallinity, dissolution, and agglomeration. In all, the general mechanisms by which it causes toxicity lie on its capability to initiate the formation of reactive species, cytotoxicity, genotoxicity, and neurotoxicity, among others.

\section{Introduction}

Nanotoxicology is an aspect of nanoscience that deals with the study of the adverse effects of engineered nanomaterials or nanoparticles on living organisms. The ever-increasing application of engineered nanoparticles for biomedical application has raised serious concerns about their safety in humans. Nanoparticles (NPs) are widely used as nanomedicine and nanocarriers of drugs, due to their small size and exclusive properties [1, 2]. However, their size [3], morphology, surface functional groups [4], and dose-dependent properties [5] may also be responsible for their toxicity towards normal, healthy human cells, tissues, and organs. Several studies have shown that chemically synthesized NPs have high toxicity on human cells due to the presence of synthetic chemicals as surface functional and capping agents, compared to biosynthesized nanoparticles that possess biocompatible surface functional groups [6]. On the contrary, certain biosynthesized nanoparticles also exhibit toxicity upon reaction with cells, while disintegrating into its simpler forms or due to accumulation $[7,8]$. The scope of nanotoxicology is aimed at identifying potential hazards that are useful for the safety evaluation of nanomedicines. This review consulted current literature and presented recent information about the toxic effects of nanoparticles.

\section{Properties of Nanoparticles That Influence Toxicities}

The NPs properties that influence toxicity are size, surface area, shape, aspect ratio, surface coating, crystallinity, dissolution, and agglomeration.

2.1. Size and Surface Area. As nanoparticle size decreases, the ratio of surface area to volume exponentially increases, which in turn increases biological and chemical reactivities [9]. For instance, when the size of the NP decreased from 30 to $3 \mathrm{~nm}$, the number of surface molecules expressed increased from 10 to $50 \%$ [10]. The cytotoxicity of nanomaterials results from the interaction between the nanomaterial surface and cellular components. Thus, even when nanoparticles have the same chemical composition, they can have a significantly different level of cytotoxicity depending on surface area and particle size. In other words, NPs have higher toxicity in comparison to the bigger particles with similar compositions.

Chao et al. [11] reported silver NPs' size-dependent acute toxicity in $\mathrm{BALB} / \mathrm{c}$ mice after intraperitoneal administration of silver nanoparticles, which had diameters of 10,60 , and $100 \mathrm{~nm}$. Histopathological changes such as the thymus cortex apoptosis; focal necrosis, single-cell necrosis, vacuolation, and congestion in the liver; and congestion in the spleen were only seen after administering $10 \mathrm{~nm}$ silver nanoparticles and not for 60 and $100 \mathrm{~nm}$ silver nanoparticles. Thus, smaller nanoparticles have greater acute toxicities in mice.

$\mathrm{Du}$ et al. [12] investigated cardiovascular toxicity of different sizes of amorphous silica NPs (90, 60, and $30 \mathrm{~nm}$ ) and $600 \mathrm{~nm}$ of fine silica NPs after intratracheal instillation in rats. The silica concentrations in serum and heart were evaluated using inductively coupled plasma optical emission spectroscopy. Blood levels of inflammation-related proteins, cytokines, and tumor necrosis factor were found higher in rats administered fine silica particles.

In the case of the administration of nanoparticles via inhalation, different sizes of nanoparticles showed specific distribution patterns in the respiratory tract. The toxicological evaluation of the response to inhaled nanoparticles requires knowledge of the dose of nanomaterials deposited in the respiratory tract. Braakhuis et al. [13] showed sizedependent pulmonary inflammation after inhalation of 15 and $410 \mathrm{~nm}$ of silver NPs. The NPs inhaled were not removed 
sufficiently compared to the large particles through the mechanisms of macrophage clearance in lungs and that could cause lung damage.

Lopez-Chaves et al. [14] evaluated subcellular location, toxic effects, and tissue distribution of three different gold NPs' sizes. They used particles of 10,30 , and $60 \mathrm{~nm}$ sizes and assessed in vivo distribution after intraperitoneal administration in the rat. The gold nanoparticles of 10 and $30 \mathrm{~nm}$ crossed the membrane of the nucleus, consequently favoring breaks in DNA. These 10 and $30 \mathrm{~nm}$ gold NPs seemingly accumulate more in liver, kidney, and intestine than $60 \mathrm{~nm}$ gold nanoparticles. The highest accumulation of $60 \mathrm{~nm}$ particle was observed in the spleen. Thus, the larger the sizes of gold NP, the higher they accumulate in the spleen.

Nanoparticles' absorption from the GI tract is a multistep process; a function of mucus layer interaction, enterocytes contact and assimilate through a cellular entry or paracellular transport [15]. NPs less than $100 \mathrm{~nm}$ get absorbed by intestinal cells, unlike the bigger NPs $(300 \mathrm{~nm})$ [16]. Smaller NPs' $(100 \mathrm{~nm})$ absorption in lymphatic tissues is higher than in cells of the intestine [16]. Although some studies stated otherwise, endocytosis remains the main mechanism mostly common for NPs' uptake into epithelial cells of the intestine [16].

In summary, NPs have larger surface areas and higher particle numbers per unit mass in comparison with the bigger particles (Table 1). The body reacts in a different way with similar mass composed of billions of NPs in comparison with many microparticles. The engineered nanoparticles possess high surface reactivity, as well as high surface area, which could result in producing higher reactive oxygen species level, thus leading to cytotoxicity and genotoxicity $[17,18]$.

2.2. Shape. Shape is an important factor of nanoparticles that play a vital role in determining their biological reactivity as well as toxicity. The typical shapes of nanoparticles are sphere, cylinder, cube, sheet, or rod (Figure 1). The shape of the nanoparticle is important in determining its cellular uptake.

The cellular uptake of carbon nanomaterial of spherical shape and tubes of multi-graphitic sheets was observed in epithelial tissues of both gut and gill, but not of cube-shaped carbon nanoparticles [19]. Silver nanoplates were found to be more harmful than silver nanospheres in zebrafish (Danio rerio) embryos [20]. The spherical nanoparticles are taken up in greater numbers in cells compared to the other shapes [21]. Gold nanorods cause less accumulation of autophagosome than gold nanospheres [22]. Steckiewicz et al. [23] examined the cytotoxic properties of gold NP of stars, rods, as well as spheres against human fetal osteoblast, osteosarcoma, and pancreatic duct cell line using MTT assay. The star-shaped gold nanoparticles are the most cytotoxic against human cells. Both cytotoxicity and anticancer potentials of gold nanoparticles depend on shape. Mesoporous silica nanoparticles have shown potential as a drug carrier in oral drug delivery. The needle-shaped nanoparticles exhibit more toxicity than those with spherical shape, because of their improved multiple endocytic mechanisms, internalization rates, and more efficient adhesiveness to the surface of the target cell [24-26].

2.3. Aspect Ratio. A nanoparticle aspect ratio is the width to height ratio. An aspect ratio of 1 represents a spherical particle, while nanotube has an aspect ratio close to zero. The greater the NPs' aspect ratio, the higher the toxicity of the NPs [27]. Aspect-ratio-dependent toxicity is generally observed in the lung. The nanofibers with about $150 \mathrm{~nm}$ thickness and 2, 5, and $10 \mu \mathrm{m}$ length show asbestosis, mesothelioma, and lung cancer, respectively [27]. Muller et al. [28] studied the pulmonary toxicities of carbon nanotube with a high aspect ratio in Sprague-Dawley rats following administration directly into the trachea. Carbon nanotube samples caused significant protein exudation and granulomas on the peritoneal side of the diaphragm [28].

Li et al. [29] systematically studied the effect of NPs of mesoporous silica with different aspect ratios of 5, 1.75, and 1 on their in vivo toxicity, excretion, and biodistribution after administration through the oral route. With a reduction in the aspect ratio, systematic absorption through organs, e.g., the small intestine, increased while the excretion via urine reduced. Renal toxicity which depends on shape of silica nanoparticles was reported [29].

2.4. Crystallinity. The type of crystalline structure may affect the toxicity of nanomaterials. Polymorphs, the different crystalline structures of the same chemical composition showed different chemical and physical properties. Lai et al. [30] reported cytotoxicity of 10-hydroxycamptothecin (HCPT) nanoparticle dispersions, which depends on the polymorph, in both in vivo and in vitro studies. Three 10hydroxycamptothecin polymorphic nanoparticle dispersions, i.e., pan-cake, prismatic, and needle forms, were made and characterized. The cytotoxicity results indicated that all the different HCPT nanoparticles' cellular toxicities depended on size and shape. However, the needle-shaped HCPT nanoparticles are more potent in apoptotic response in cancer cells despite similar cellular uptakes as prismatic nanoparticles. This effect may explain the preference for polymorph with different thermodynamic properties, including lattice energy. Andersson et al. [31] also reported titanium dioxide NPs' uptake and toxicity in A549 lung epithelial cells, which were polymorph-dependent. These reports lay emphasis on the significance of the accurate characterization of the polymorphic form (crystalline structure) of nanoparticles for reliable assessment of toxicity.

2.5. Surface Coating or Surface Functionalization. Surface coatings of nanoparticles are applied in order to modify its properties. The surface of a particle (the "core") is covered with a variety of layer(s) (the "shell"). The objective of the surface coating may be to tailor its stability, wettability, dissolution, or functionality. The surface coating can convert noxious particles to be nontoxic while less harmful particles may become more toxic due to bioavailability. Xu et al. [32] 
TABle 1: Particle size, surface area, and number.

\begin{tabular}{lcc}
\hline Diameter of particle $(\mathrm{nm})$ & Surface area of particle $\left(\mu \mathrm{m}^{2} \mathrm{~cm}^{-3}\right)$ & Number of particles $\left(\mathrm{N} \mathrm{cm}{ }^{-3}\right)$ \\
\hline 5 & 12000 & 153000000 \\
20 & 3016 & 2400000 \\
250 & 240 & 1200 \\
5000 & 12 & 0.15 \\
\hline
\end{tabular}

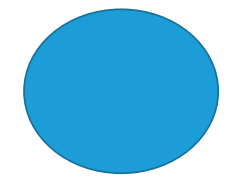

Spherical

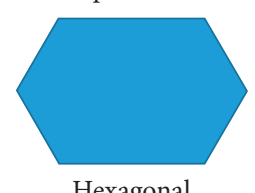

Hexagonal

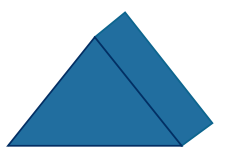

Prism

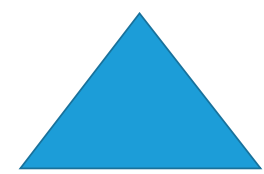

Triangular

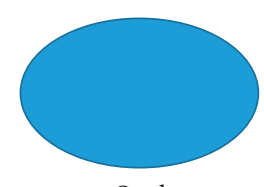

Oval

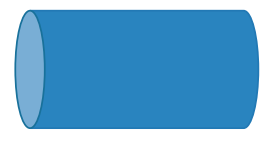

Rod

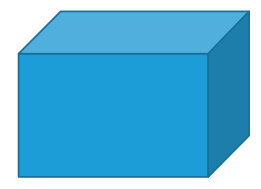

Cubic

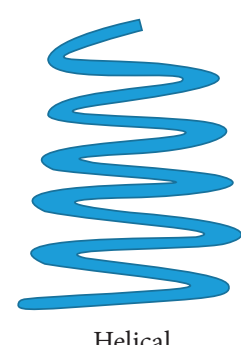

Helical
Figure 1: Typical shapes of nanomaterials.

performed an in vitro evaluation of the toxicity of iron oxide nanoparticles coated with silica $\left(\mathrm{Fe}_{3} \mathrm{O}_{4} / \mathrm{SiO}_{2} \mathrm{NP}\right)$ on the cells of HeLa and A549. Reports indicate that surface passivation of NPs decreases the alteration of iron homeostasis and oxidative stress. As a result of this, there is overall toxicity reduction during cell internalization when compared to nanoparticles that are not passivated.

In a separate study, the iron oxide NPs coated with polyethyleneimine (PEI) were reported to significantly exhibit higher uptake than PEGylated iron oxide nanoparticles in both cancer cells and macrophages which resulted in severe cytotoxicity [33]. PEI-coated iron oxide NPs were more efficiently internalized than PEGylated iron oxide NPs despite having the same nanoparticle sizes, which could be the result of the cationic NPs' affinity to the protein domains or negative head groups of phospholipids on cellular membranes. Consequently, it is imperative to put surface coatings of NPs into consideration in toxicity studies.

2.6. Dissolution. The dissolution ability of nanoparticles is a significant property that determines safety, uptakes, and associated toxic mechanism. Two identical NPs of similar composition and size may have completely different behavior in dissolution, depending on different surface modification [34]. Nanoparticles that undertake media dissolution before uptake by the organisms usually have clear ion channels and ion transporters as the preferred cellular entry route.

2.7. Agglomeration. Nanomaterials are likely to agglomerate in solution due to their high free surface energy [35]. To avoid agglomeration, nanomaterials are shielded with protective agents. The toxicity of nanomaterials is also dependent on whether or not agglomeration occurred. The agglomeration of nanoparticles could be a potential inducer of inflammatory lung conditions in humans [36]. The agglomeration-dependent toxicity of nanomaterials is more commonly observed in carbon nanotubes and oxide nanoparticles. The well-dispersed carbon nanotubes have been reported as having less toxicity than the agglomerated carbon nanotubes [37]. Zook et al. [38] showed the significance of agglomeration control by demonstrating that large silver NPs agglomerate significantly causing less hemolytic toxicity compared to small agglomerates.

\section{General Mechanism of Nanoparticle Toxicity}

The general mechanism by which metallic oxide nanoparticle induces toxicity is a joint function of the properties of the nanoparticle and its corresponding ability to induce ROS, and cause toxicity to cells, genes, and neurons.

3.1. Nanoparticle-Induced Oxidative Stress. Oxidative stress is among the commonly reported stresses that nanoparticles induce following exposure on a cellular level. Oxidative stress can be broadly defined as a lack of balance between antioxidants' activities and the production of oxidants [39]. A state of oxidative stress arises via increase in ROS production favored over antioxidants [40]. ROS are generally produced in the form of by-products of biochemical reactions, including neutrophil-mediated phagocytosis, enzymatic metabolism of cytochrome $\mathrm{P} 450$, and mitochondrial respiration [41], and commonly include peroxynitrite (ONOO-), nitric oxide $(\mathrm{NO})$, hydroxyl radical $(\bullet \mathrm{OH})$, hydrogen peroxide $\left(\mathrm{H}_{2} \mathrm{O}_{2}\right)$, and superoxide radical $\left(\mathrm{O}_{2} \bullet-\right)$ [41]. The ROS attack nucleic acids, proteins, lipids, and most vital biomolecules which can lead to an NADPH-like system activation, electron transport chain impairment, mitochondrial membrane depolarization, and damage to the mitochondrial structure [42].

Oxidative stress constitutes significant adverse effects in the use of nanoparticles, as it may generate oxidants and have the capacity to stimulate ROS generation partly as a result of relative stability of free radical intermediates, which occur on particles' reactive surfaces, or as NPs-induced cellular response, or redox-active groups caused by NPs functionalization, especially with the ability of the NP to interfere with cellular uptake [43]. Such imbalance induced by nanoparticles directly or indirectly can lead to drastic effects that may lead to cytotoxicity [44]. ROS induced by NPs can cause damage to genetic materials, including cross- 
linking of DNA, breakage of DNA strand, and genetic mutations. NPs can also increase ROS production by activating inflammatory cells, including neutrophils [45].

Zinc Oxide NPs (ZnONPs) are widely applied for various purposes ranging from fillers, a component of creams, powders, dental creams, absorber of UV radiation, and biosensors [46]. Nevertheless, studies have shown that zinc oxide can result in oxidative stress leading to damage on a cellular level. A study was conducted on human liver cells (HepG2) that are exposed to 14-20 lg per ml of ZnONP and are found to cause oxidative stress-mediated damage to DNA and ROS-triggered mitochondria-mediated apoptosis HepG2 [47]. ZnONPs also reduce cell viability and trigger apoptosis in primary astrocytes along with increased levels of intracellular ROS [48]. According to Hou et al. [49], ZnONPs induce the failure of minichromosome maintenance with a corresponding DNA replication disorder in different periods (G1, M, and G2 phase) in the cell cycle pathway.

Super paramagnetic iron oxide nanoparticles, which have various uses in magnetic resonance imaging distinction, improvement, immunoassays as well as drug targeting systems for cancer, were found to cause oxidative stress in addition to disturbance in iron homeostasis exposures of the core of the iron oxide and can cause oxidative stress that could be linked with disorders in neurological system [50-52].

Silver NP (AgNp) was found in several consumer items owing to their excellent anti-microbial activities. However, several reports have concluded that they have cytotoxic properties owing to oxidative stress. One report attributed oxidative stress-mediated programmed cell death of AgNPs in Candida albicans through the accumulation of intracellular ROS as well as other targets of the cells leading to changed ultrastructure, cellular morphology, ergosterol content, membrane microenvironment, and membrane fluidity [53]. Another study conducted on mice administered treatment orally using AgNps coated with polyvinylpyrrolidone (PVP-AgNPs) and reported permanent alterations in genes and DNA damage in several tissues [54]. Finally, the silver species oxidation in AgNPs after their quick releasing from decreased silver-rich NP after being autophaghed by lysosymes results in cellular toxicity modulated by ROS generation [55]. The same holds true for gold nanoparticles (AuNPs) which are widely used in cancer treatments; however, they have been reported to have oxidative stress-induced cytotoxicity on several cell lines, including the cells of HeLa, HepG2, and PMBC by generating ROS $[56,57]$.

Ahamed et al. [58] carried a study and concluded that $\mathrm{Bi}_{2} \mathrm{O}_{3}$ nano particles cause dose-dependent apoptosis and cytotoxicity in cells of MCF-7. However, they found that supplementing external antioxidants, $\mathrm{N}$-acetyl-cysteine, altered the $\mathrm{Bi}_{2} \mathrm{O}_{3}$ nanoparticles' cytotoxicity effectively, thereby suggesting that $\mathrm{Bi}_{2} \mathrm{O}_{3}$ nano particles caused the cytotoxicity by alteration of redox homeostasis.

In addition to metallic NPs, nonmetallic nanoparticles can also cause oxidative stress. Ceramic NPs which are usually applied in drug delivery were shown to induce oxidative stress leading to cytotoxicity in the brain, heart, liver, and lungs, and also carcinogenic and teratogenic properties [59]. Also, silica nanoparticles ( $\mathrm{SiNP}$ ) were shown to initiate a time- and dose-dependent $\mathrm{NO} / \mathrm{NOS}$ imbalance and oxidative stress, resulting in inflammation and dysfunction of endothelium [60]. Carbon nanotubes (CNT) were also shown to induce oxidative stress-related toxicity. Shvedova et al. [61] demonstrated that in addition to free radicals, CNT cellular uptake induced oxidation of polyunsaturated fatty acids and caused cellular apoptosis.

\subsection{Cytotoxicity of Nanoparticles: Biochemical and Molecular} Mechanisms of Cytotoxicity. In addition to cytotoxicity induced by ROS generation discussed earlier, cytotoxicity induced by nanoparticles can be caused by various physicochemical, biochemical, and molecular mechanisms.

3.2.1. Physicochemical Mechanisms. As noted earlier, particle size could contribute to cytotoxic potency because smaller nanoparticles typically possess larger surface areas which enable interactions with components of the cells, including carbohydrates, fatty acids, proteins, and nucleic acids. Moreover, these very small nanoparticles have more likelihood of entering cells, resulting in damage to cells [62]. Jiang et al. [62] concluded that crystal type has a significant effect on cytotoxicity with amorphous $\mathrm{TiO}_{2}$ being the most cytotoxic form. Particle shape was also found to have a direct effect on cytotoxicity. Rod-shaped $\mathrm{Fe}_{2} \mathrm{O}_{3}$ NPs produce higher responses to cytotoxicity than $\mathrm{Fe}_{2} \mathrm{O}_{3}$ NPs with sphere shape in a cell line of murine macrophage (RAW 264.7), along with higher levels of necrosis, ROS production, inflammatory response, and leakage of lactate dehydrogenase (LDH) [63]. In addition, $\mathrm{CeO}_{2}$ nanoparticles with rod shape were reported to give substantial tumor necrosis factor-alpha (TNF) and LDH release in the cell lines of murine macrophage, whereas none of the cubic or octahedron shape could give significant responses [64].

Surface charge of particles could also have an effect on the nanoparticles' cellular uptake and their interaction with biomolecules and organelles, thereby directly influencing NP cytotoxicity with the toxicity increasing as surface charge increased. A study on the cell line of human hepatoma (BEL7402) on several iron NPs with different surface charges concluded that the more positive charge NP has more electrostatic interaction with cells leading to more endocytic uptakes [65]. This correlated with another study which concluded that positively charged ZnONPs produced more cytotoxicity in cells of A549 than particles with negative charges despite having similar size and shape [66], which was attributed to the interaction of particles of positive charges with the Glycosaminoglycan molecule (which is negatively charged) in the mammalian cell membrane leading to the NP being more internalized [67], and the same scenario can be applied in positive charge NPs that interact with negative charge DNA, resulting in damage to DNA.

Dendrimers, which are widely used commercially in drug, gene, and siRNA delivery, with the anionic or PEGylated dendrimers showing low toxicity compared to 
cationic dendrimers [68], decrease cell integrity and permeability, and interact with the lipid bilayer of the biological membrane [69, 70]. PAMAM dendrimers have also been shown to have a cytotoxic effect because their surface amino groups impart a cationic charge, which upon endocytosis results in DNA damage, mitochondrial damage, oxidative stress, and consequently apoptosis [71].

3.2.2. Molecular and Biochemical Mechanisms. The perturbation of $\mathrm{Ca}^{2+}$ (intracellular calcium) induced by nanoparticles is a major cause of cytotoxicity induced by NPs and linked to energetic imbalance, metabolic imbalance, and cellular dysfunctions [72]. Although $\mathrm{Ca}^{2+}$ is among the major signaling molecules involved in the transduction of cell signal in the regulation of cellular metabolism and energy output, its increase has a direct toxic effect on cellular mitochondria which respond in an apoptic pathway via selectively releasing cytochrome $\mathrm{c}$ or by improved ROS production and making an inner pore of mitochondrial membrane open, all of which lead to cell death [73]. ZnONPs increase $\mathrm{Ca}^{2+}$ and influx of extracellular calcium inflicted by membrane disruption through lipid peroxidation, malondialdehyde (MDA) causing cytotoxicity, and disruption in hemostasis [74]. A study by Lai et al. [75] reported a reduction in mitochondrial membrane potential (MMP) following $\mathrm{ZnO}$ exposure in alveolar adenocarcinoma cells (A549) and bronchial epithelial cells (BEAS-2B) of humans, indicating a higher risk of early apoptosis [75]. Li et al. [76] reported that $\mathrm{ZnONP}$ appeared to physically squeeze mitochondrial bodies in $\mathrm{HaCa}$ cell lines [76]. $\mathrm{TiO}_{2}$ leads to loss of mitochondrial membrane potential in lung A549 cells and neuronal cells (PC12) $[77,78]$. $\mathrm{Fe}_{3} \mathrm{O}_{4}$ induced loss of mitochondrial membrane potential in human hepatoma cells (BEL-7402) and "human mesenchymal stem cells" (hMSCs) $[65,79] . \mathrm{Bi}_{2} \mathrm{O}_{3}$ NPs were also reported to cause low MMP together with a greater bax/bcl-2 genes expression ratio, inducing cell apoptosis via the pathway of mitochondria [58]. Recently done studies showed that binding of proteins to metal oxide nanoparticles such as $\mathrm{FeO}, \mathrm{SiO}_{2}, \mathrm{TiO}_{2}$, or $\mathrm{ZnO}$ NPs could lead to protein denaturation or minor changes in conformation, with irreversible proteins binding to NPs [80]. Also, $\mathrm{Cu}$ and $\mathrm{Zn}$ ions were shown to inactivate some metalloproteins through the dislodging of metallic ions in them [81].

3.2.3. Cells Cycle Arrest. Cell divisions comprise two successive progressions, Mitosis (M), which is the nuclear division and interphase process, including G1, G2, and $S$ phases. DNA replication takes place in the $S$ phase and is preceded by the G1 phase within which the cells prepare for the synthesis of DNA; then it is followed by the G2 phase in which cells prepare for $\mathrm{M}$. Cells within G1 phase may enter a state of resting known as G0, which is responsible for most part of the nonproliferating and nongrowing cells in humans [82].

Recently, it has been shown that nanoparticles' cytotoxic effect may not only lead to cell death but also to cell proliferation suppression that occurs once cells are arrested in at least one phase of the cell cycle (G2/M phase, $S$ phase, or G0/ G1 phase) [72]. Cells arrested within cell cycle either accumulate much damage leading to apoptosis or fix the damage [72].

Cell cycle arrest can be specific to certain types of cells at specific phases, for instance, nickel oxide NP (NiONP) exposure led to a significant decrease in G0/G1 in the cell line of A549 and a significant increase in the G0/G1 phase in the cell line of BEAS-2B. Similarly, the G2/M phase in the cell line A549 significantly increased and the G2/M in the cell line of BEAS-2B significantly decreased, whereas only the cell line of BEAS-2B significantly affected the $S$ phase [83]. The type of nanoparticle also affects the cell cycle. In $\mathrm{HaCa} \mathrm{T}$ cells, exposure to $\mathrm{CuO}$ and $\mathrm{ZnO}$ NPs led to G2/M phase arrest, whereas $\mathrm{TiO}_{2}$ exposure led to $\mathrm{S}$ phase arrest $[76,84,85] . \mathrm{Fe}_{3} \mathrm{O}_{4}$ and $\mathrm{Al}_{2} \mathrm{O}_{3}$ resulted in an increase in the phase of sub-G0 of hMSFs. Also, cells of A549 was arrested in the G2/M phase following exposures to $\mathrm{ZnO}, \mathrm{NiO}$, and $\mathrm{CuO}$, but upon $\mathrm{Fe}_{2} \mathrm{O}_{3}$ exposure experienced no cell cycle change $[75,86]$.

3.3. Genotoxicity of Nanoparticles. The mechanism behind nanoparticle-associated genotoxicity is majorly due to the overproduction of reactive nitrogen (RNS) species and ROS, which results in increased oxidative stress and hence oxidative damage to the genetic material [87]. The NPs-mediated production of ROS and RNS can be due to intrinsic production, interaction with cell target, and/or inflammatory reaction. The resultant damage to the genetic material can be direct or indirect primary clastogenic or secondary (aneugenic, and DNA adduct production) genotoxicity [88]. The primary toxicity occurs due to the interaction of the NPs themselves with the DNA, whereas in the secondary genotoxicity, the genetic damage occurs as a result of ROS/RNS produced/carried by the NPs [89]. In the indirect primary clastrogenic mechanism, exocyclic DNA adducts are produced via unsaturated aldehydes produced as a result of ROSmediated primary lipid oxidation. The secondary aneugenic mechanism's major consequence is chromosomal loss due to nondisjunctioning in the anaphase as a result of ROS and or RNS-induced protein oxidative lesions that affect the function of the mitotic apparatus [88]. Many scientific studies are in support of nanoparticles-induced genotoxicity. For example, Kisin et al. [90] reported that single-wall carbon nanotubes (SWCNTs) caused single- and double-strand DNA lesions in Chinese hamster fibroblasts (V79 cell line) at $96 \mu \mathrm{g} / \mathrm{cm}^{2}$. In a different study, AgNPs at different concentrations were found to cause significant DNA damage in S. cerevisiae [91], larvae of the mulberry silkworm [92], adults of the microcrustacean C. cornuta [93], and abnormalities in micronuclei and nuclear of zebrafish (D. rerio) [94]. AgNPs' genotoxicity was also reported in microbes $[95,96]$ and plants [97-99]. A summary of reported in vitro and in vivo studies for the genotoxic effects of NPs is presented in Table 2.

3.4. Neurotoxicity of Nanoparticles. Neurotoxicity is a reversible or irreversible side effect that may affect the structure, function, or chemistry of the neurons in the nervous system [133]. Though the research community 
TABLE 2: In vitro and in vivo studies for the genotoxic effect of NPs.

\begin{tabular}{|c|c|c|c|}
\hline S/no. & Nanoparticles & In vitro studies & In vivo studies \\
\hline \multirow{3}{*}{1.} & Carbon-based NPs & & \\
\hline & Single-wall carbon nanotubes (SWCNTs) & $\begin{array}{l}\text { Single- and double-strand DNA lesions in } \\
\text { Chinese hamster fibroblasts (V79 cell line) } \\
\text { for } 3 \mathrm{~h} \text { at } 96 \mu \mathrm{g} / \mathrm{cm}^{2}[90] .\end{array}$ & $\begin{array}{c}\text { Genotoxicity via inhalation exposure in } \\
\text { mice (C57BL). Causes immediate } \\
\text { inflammatory reaction, fibrosis, oxidative } \\
\text { stress, and hyperplasia }[100] .\end{array}$ \\
\hline & Multiwall carbon nanotubes (MWCNTs) & $\begin{array}{l}\text { Induce apoptosis in the stem cells of mouse } \\
\text { embryo via P53 protein activation; cause } \\
\text { DNA damage [101-103]. }\end{array}$ & $\begin{array}{c}\text { Absence of genotoxicity in rats }[104,105] \\
\text { Causes DNA damage in the lung cells, } \\
\text { bone marrow, and leucocytes of mice } \\
{[106,107] .}\end{array}$ \\
\hline 2. & $\begin{array}{l}\text { Silver NPs: gained wide application in both } \\
\text { food and medical purposes owing to its } \\
\text { antimicrobial activity [108] }\end{array}$ & $\begin{array}{l}\text { The micronucleus assay and comet assay } \\
\text { confirmed the mutagenic and genotoxic } \\
\text { effect of AgNPs }[17,109-112] \text {. }\end{array}$ & $\begin{array}{l}\text { Causes DNS damage in mice lung cells } \\
\text { and testis in size-dependent toxicity [113] }\end{array}$ \\
\hline 3. & $\begin{array}{l}\text { Gold NPs: useful in gene and drug delivery } \\
\text { as well as deep tissue imaging }\end{array}$ & $\begin{array}{l}\text { AuNPs on various cell lines showed } \\
\text { chromosomal aberration, micronuclei } \\
\text { formation, oxidative DNA damage, and } \\
\text { strand lesions [114-117]. }\end{array}$ & $\begin{array}{l}\text { Negative genotoxic results in mice but } \\
\text { chronic and acute intraperitoneal } \\
\text { administration of } 10 \text { and } 30 \mathrm{~nm} \text { Au NPs } \\
\text { induced DNA damage evaluated by come } \\
\text { assay in the liver, blood, and cerebral } \\
\text { cortex cells of rats [118]. }\end{array}$ \\
\hline
\end{tabular}

A $20 \mathrm{~nm} \mathrm{TiO}_{2}$ NPs induced genotoxicity in Syrian hamster embryo fibroblasts at various concentrations ranging from $0.5-10 \mathrm{mg} / \mathrm{cm}^{2}$ via the production of ROS

Titanium dioxide $\left(\mathrm{TiO}_{2}\right)$ NPs: titanium dioxide $\left(\mathrm{TiO}_{2}\right)$ NPs porous $\mathrm{TiO}_{2}$ [119],

4. $\quad \mathrm{TiO}_{2}$ nanotubes [120], and $\mathrm{TiO}_{2}$ smart drug delivery carriers; also approved

in EU as a food additive (E171) as a result of the NPs interaction with the cell membrane [122]. A dose-dependent

DNA lesion has been reported upon exposure of HEpG-2 cell to a range of $\mathrm{TiO} 2$ NPs concentrations $(10-100 \mu \mathrm{g} / \mathrm{mL})$ [123].

A dose-dependent micronuclei production and DNA strand breakage have been reported in human lymphocytes by comet and micronucleus assay [124].
Iron oxide $\left(\mathrm{Fe}_{2} \mathrm{O}_{3}\right) \mathrm{NPs}$ : magnetite $\mathrm{Fe}_{2} \mathrm{O}_{3}$ Induce dose-dependent DNA damage

5. NPs is an important candidate for drug when rat alveolar macrophages and human delivery and a potential carrier for brain- monocyte cells at concentrations of 5.1 and targeted drug delivery [88]

6.

Silica NPs

Organic NPs: organic nanoparticles could

7. be colloidal, e.g., polymeric NPs, solid lipid NPs, or vesicular, e.g., liposomes

$$
10.2 \mu \mathrm{g} / \mathrm{cm}^{2} \text { [126]. }
$$

Amorphous fumed silica-induced significant oxidative DNA damage in human colon epithelial cells line after $24 \mathrm{~h}$ of exposure [129]. Similarly, exposing human lymphoblastoid cells to $100 \mathrm{~nm}$ ultrafine crystalline $\mathrm{SiO}_{2}$ NPs during 6, 24, and $48 \mathrm{~h}$ at a range of concentrations (0a $20 \mathrm{mg} / \mathrm{ml}$ ) induced genotoxicity [130].

Dendrimers are hyper-branched polymers which have been used as a promising drug delivery vehicle.

Cationic dendrimers showed increased oxidative stress and DNA damage in human neural progenitor cells dependent on surface group density and number of particles [132]. has centered its efforts on developing a brain-targeted drug delivery system using smart NPs, there is less information available on the neurotoxicity of these particles. Various research papers suggested that the neurotoxicity of the NPs is due to oxidative stress triggered by free radical activity $[134,135]$. A summary of the neurotoxic effects of selected nanoparticles is presented in Table 3.
Micronucleus induction has been demonstrated after administration $[127,128]$.
Genotoxicity of $\mathrm{TiO}_{2}$ particles has been reported in mice after 5 days of oral exposure in addition to DNA deletions upon exposure during fetal development [125].

Genotoxicity has been reported in rats after a short period ( 1 and 3 days) inhalation of a freshly generated aerosolized amorphous $\mathrm{SiO}_{2}$ of size 37 and $82 \mathrm{~nm}$, the toxicity was estimated after $24 \mathrm{~h}$ to 2 months after exposure [131]. 
TABLE 3: Neurotoxic effects of some nanoparticles.

\begin{tabular}{|c|c|c|}
\hline Nanoparticles & Toxic effects & References \\
\hline Carbon nanotubes & $\begin{array}{l}\text { Inflammation in the olfactory bulb. Promotes ROS formation, increases oxidative stress, inhibits cell } \\
\text { proliferation and apoptosis. }\end{array}$ & {$[136,137]$} \\
\hline Silver NPs & $\begin{array}{l}\text { Increases oxidative stress and decreases the anti-oxidation capacity of the antioxidative enzymes in } \\
\text { frontal cortex and hippocampus of mice. }\end{array}$ & [138] \\
\hline $\begin{array}{l}\text { Titanium oxide } \\
\text { NPs }\end{array}$ & $\begin{array}{l}\text { Induces oxidative stress, neuroinflammation, genotoxicity, neurotransmitters dysregulation, } \\
\text { disrupted signaling pathways, and plasticity of the synapse. }\end{array}$ & [139-141] \\
\hline Iron oxide NPs & $\begin{array}{l}\text { Neuroinflammation, apoptosis, and immune cell infiltration have been reported as a side effect of } \\
\text { exposure to iron oxide nanoparticles. }\end{array}$ & [142-145] \\
\hline Silica & $\begin{array}{l}\text { It causes cognitive dysfunction impairment, synaptic changes, an increase in oxidative stress, and } \\
\text { microglial function alteration. }\end{array}$ & {$[146,147]$} \\
\hline Organic NPs & $\begin{array}{l}\text { It causes dose-dependent inflammation, oxidative stress, neuronal apoptosis, and accumulation in the } \\
\text { frontal cortex. }\end{array}$ & {$[134,148-153]$} \\
\hline
\end{tabular}

\section{Studies on Specific Nanoparticles and Their Associated Toxicity}

The basic mechanism of metal oxide nanoparticle toxicity is based on its colloidal dispersion, homeostasis alteration, and accumulation. The colloidal dispersion of metal oxide nanoparticles leads to ions of metals and oxygen, where the metals accumulate, alter the homeostasis of cells, and bind with cell organelles to cause toxic effects. The oxygen ion, being singlet oxygen, produces ROS, increases oxidative stress, and leads to lipid peroxidation. In the second case, the slow release of metal ions from the nanoparticles alters the cellular homeostasis as most of the fabricated metal oxide nanoparticles are trace and essential metals that are required for the development of cells. These alterations also cause the level of metals to increase more than their threshold limit, similar to the toxicity caused by heavy metal accumulation. In the third case, highly stable metal oxide nanoparticles accumulate either on the surface of the cells or internalize into the cells. These nanoparticles accumulate and agglomerate, which causes either $1^{\text {st }}$ or $2^{\text {nd }}$ case of toxicity or just the accumulation of high metal oxide concentration which may also lead to toxic effects.

Metal nanoparticles exhibited cytotoxicity via three significant pathways [154] as shown in Figure 2:

(1) Particle characterization

(2) Dosimetry

(3) Interaction with the cells

The particle characteristics are highly dependent on the synthetic approach, which can alter their size, morphology, and surface functional groups [155]. The dosimetry, including the dose and concentration of nanoparticles to initiate toxic reactions in cells, is also dependent on the physicochemical characteristics of the metal nanoparticles [155]. The cell interaction is an independent characteristic which leads to toxicity. Sometimes, the size and morphology influence the interaction of metal oxide with the cells, yet, most of the time, it is their surface charge, stability, and surface functional groups that determine the nanoparticles' cellular interaction [156]. As suggested earlier, the smaller size of these nanoparticles allows easy by-pass through the cell membrane and then to the nucleus, which may cause alterations in DNA and mitochondrial pathways, leading to serious genotoxicity. Low stable metal nanoparticles, which are dependent on the surface charge, will release free metal ions that will accumulate inside the cell organelles and inhibit their growth via oxidative stress, similar to heavy metal accumulation [157]. However, biomolecules as surface functional groups, especially phytochemicals with antioxidant properties, rather than synthetic stabilizing and a capping agent from chemically synthesized nanoparticles, helps in reducing the release of ROS from the metal nanoparticles [158], which forms peroxides and inhibits cell growth and causes cell death [159].

4.1. Gold Nanoparticles. Gold nanoparticles are arguably the first nanoparticles that are used in commercial materials and approved by the United States Food and Drug Administration (USFDA) as nanomedicine and nanocarrier [160, 161]. Moreover, these nanostructures possess unique size-dependent surface plasmon resonance properties that made them utilizable in biosensor applications [160]. In spite of these applications, gold nanoparticles are also considered to be toxic based on the administered dose and concentration via accumulation in cells, similar to heavy metals [159]. In recent times, several studies reported different factors that can lead to cytotoxicity towards human cells. Senut et al. [162] explored the size-dependent toxicity of gold nanoparticles towards human embryonic stem cells and their neural derivatives. Particle sizes such as $1.5,4$, and $14 \mathrm{~nm}$ of gold nanoparticles were used to evaluate its neuronal differentiation, viability, DNA methylation, and pluripotency. The result of the study revealed that the chemically synthesized gold nanoparticles of size below $20 \mathrm{~nm}$ are highly toxic to stem cells by altering cellular DNA methylation and the hydromethylation pattern [162]. Biosynthesized gold nanoparticles have shown to be an efficient anticancer drug carrier to deliver doxorubicin at the target site and cure cancer cells [163]. Thus, it is evident from these two studies that the toxicity of gold nanoparticles depends on the synthesis approach, which affects their size, morphology, topology, and surface functional group.

Recently, Jo et al. [164] evaluated the in vitro and in vivo toxicity, as well as estimated the oral absorption and tissue distribution biokinetics of orally administered, chemically 


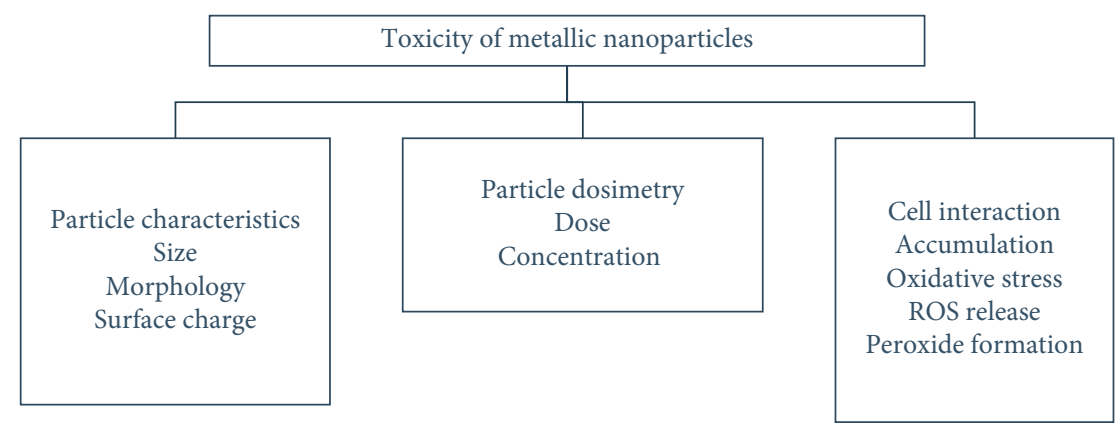

FIGURE 2: Characteristics and mechanisms of metal nanoparticles toxicity.

synthesized gold nanoparticles using human and rat intestinal cells for 14 days. The result revealed that the gold nanoparticles were nontoxic for $24 \mathrm{~h}$ in terms of membrane damage, oxidative stress, and cell proliferation inhibition. However, they also revealed that these nanosized gold particles are toxic after 14 days exhibiting long-term and high concentration exposure dependent toxic reactions [164]. Similarly, there are several studies which demonstrate that gold nanoparticles are toxic to cancer cells and not to normal healthy cells $[165,166]$. Semmler-Behnke et al. [167] showed that gold nanoparticles can accumulate in the fetus of a rat via maternal blood and can lead to toxicity towards the fetus [167].

4.2. Silver Nanoparticles. Silver nanoparticles are an important set of nanosized particles that are widely synthesized for various applications, next to gold [168]. Bulk silver possess antimicrobial activities to a certain extent, whereas nanosized silver particles possess exclusive antimicrobial properties to inhibit the growth of specific microbes, including bacteria, fungi, algae, and viruses [169]. The production of reactive oxygen species (ROS) and elevating the oxidative stress in the microbial cells are significant factors that lead to their enhanced antimicrobial activities [170]. Also, silver nanoparticles are toxic towards cancer cells by releasing ROS, specific to cancer cells [171]. The in-depth analysis of literature has revealed that only biosynthesized silver nanoparticles exhibit anticancer activity [172]. This evidence confirms that silver nanoparticles activate or enhance the immobilization of biomolecules into the cancer cells, which improve their anticancer property [173]. Even though they show toxic reactions towards microbes and cancer cells, several studies demonstrated that silver nanoparticles are less toxic or nontoxic towards healthy human cells. Kim et al. [174] examined the cytotoxicity of silver nanoparticles towards human hepatoma cells via oxidative stress. The results revealed that there is a negligible amount of free silver ions that are exposed from the nanoparticles to the cell culture. It is noteworthy that the nanoparticles are stable in the cell culture medium and agglomerate in the cellular cytoplasm and nuclei, which induces intracellular oxidative stress. In addition, the cytotoxicity of silver nanoparticles is found to be similar to the silver ions. However, the nanoparticle-mediated oxidative stress and DNA damage can be reduced by the antioxidant
$N$-acetylcysteine [175]. Similarly, Ahamed et al. [176] demonstrated that the silver nanoparticles are toxic to the cells of the skin, brain, liver, lung, and reproductive and vascular systems of mammals. They also confirmed that the toxic reactions are dependent on the short- and long-term exposure of nanoparticles with the cells [111, 177].

de Lima et al. [178] stated that silver nanoparticles possess the ability to trigger inflammatory reactions in human cells. Moreover, these nanosized silver particles had the ability to cross the cell membrane and reach the nucleus which causes increasing damage to the genetic material and hence genotoxicity. They also revealed the presence of biomolecules as functional groups in biosynthesized silver nanoparticles, which reduces ROS production with their antioxidant properties. Thus, they concluded that the biosynthesized silver nanoparticles are less toxic towards normal, healthy human cells, compared to chemically synthesized nanoparticles [178]. Gaillet and Rouanet [179] examined the toxicity of silver nanoparticles after their exposure towards humans via the oral route. They revealed that the silver nanoparticles cause toxic side effects mainly in the intestinal tract and liver via oral exposure. It is noteworthy that the silver nanoparticles produce free radicals and induces oxidative damage via cellular oxidative stress, which leads to inflammatory reaction-triggered toxicity and death by apoptosis or necrosis [179]. In addition, Kennedy et al. [180] showed that the human serum albumin helps in stabilizing aqueous silver nanoparticles, which inhibits the cellular uptake of particles, thereby reducing their potential exposure towards cells to reduce toxicity [180]. Likewise, Smith et al. [181] evaluated the kinetics of silver ions and particles using RAW 264.7 macrophages, wild-type C57BL/ $6 \mathrm{~J}$ mice derived bone marrow macrophages, and scavenger receptor $\mathrm{A}$-deficient $\left(\mathrm{SR}-\mathrm{A}^{(-/)}\right)$mice via in vitro analysis. Furthermore, the accumulation of silver at an increased concentration in cells may lead to Parkinson's disease [182], silver-Russell syndrome [183], and Alzheimer's diseases [184].

4.3. Copper Oxide Nanoparticles. Copper oxides belong to the family of metal oxides that possess enormous applications as bulk or microparticles. When these copper oxides are reduced to the nano-size, they behave differently than their bulk counterparts and exhibit exclusive properties [185]. Copper oxide nanoparticles are widely utilized as 
antimicrobial agents [186] and are also explored to possess anticancer activity [187], bioimaging [188], and nano-medicinal properties (Abdelhamid). Numerous studies have revealed that the copper oxide nanoparticles are highly toxic towards microbes such as bacteria [189], fungi [190], algae [191], and viruses [185] as well as cancer cells. In spite of these exclusive biomedical properties, several reports showed that copper oxide nanoparticles are also highly toxic to normal and healthy human cells [192]. Karlsson et al. [193] evaluated the toxicity of metal oxide nanoparticles such as oxides of titanium, iron, zinc, and copper with carbon nanoparticles and multi-walled carbon nanotubes (MWCNTs) using the human A549 lung epithelial cell line. The result showed that the copper oxide nanoparticles are highly toxic to lung cells by causing oxidative lesions and damaging DNA, compared to other nanosized metal oxides, carbon nanoparticles, and MWCNTs [193]. Similarly, Studer et al. [194] compared the toxicity of stabilized copper metal and degradable copper oxide nanoparticles using Chinese hamster oocytes and HeLa cells. The results revealed that the copper oxide nanoparticles disintegrated into copper ions, and free metallic copper ions inhibit healthy cells via trojan horse-type mechanism and its physicochemical parameters, especially intracellular solubility, plays a dominating effect on their cytotoxicity [194]. In addition, Fahmy and Cormier [192] demonstrated that copper oxide nanoparticles exhibit cytotoxicity in airway epithelial cells by inducing oxidative stress. Furthermore, Alarifi et al. [195] showed that copper oxide nanoparticles are cytotoxic and genotoxic towards human skin keratinocyte cells [195]. It is noteworthy that the copper oxide nanoparticles also showed toxic reactions towards human lung epithelial cells [176], cardiac microvascular endothelial cells [196], HepG2 cells, and human skin organ culture [197]. Moreover, Atha et al. [198] demonstrated that copper oxide nanoparticles are toxic to terrestrial plant models such as Raphanus sativus, Lolium perenne, and Lolium rigidum by damaging their DNA [198].

In recent times, Wongrakpanich et al. [199] stated that copper oxide nanoparticles exhibit high toxicity towards lung epithelial cells, which depends on their size. Four and $24 \mathrm{~nm}$ sized particles were used for the study and the result demonstrated that the $24 \mathrm{~nm}$ sized oxide nanoparticles of copper were highly toxic to cells, compared to $4 \mathrm{~nm}$ sized ones. They proposed that the post-internalization events of larger nanoparticles such as disintegration into their ionic state and releasing reactive oxygen lead to their higher toxicity than smaller nanoparticles [199]. In addition, Akhtar et al. [200] showed that copper oxide nanoparticles induce dose-dependent genotoxicity by stimulating ROS generation in human lung epithelial cells [200]. Likewise, Srikanth et al. [201] showed that the copper oxide nanoparticles exhibited cytotoxicity towards Chinook salmon cells by altering their morphology and inducing oxidative stress [201]. Moreover, Ude et al. [202] evaluated the toxicity of copper oxide nanoparticles and bulk copper sulphate towards differentiated and undifferentiated Caco- 2 intestinal epithelial cells. The result showed that both nano and bulk particles exhibited a concentration-dependent cytotoxicity towards undifferentiated cells. Furthermore, the study revealed that the nanoparticles stimulated the production of interleukin- 8 in Caco- 2 cells, decreasing the integrity of the cell barrier which helps in the translocation of copper ions [202]. In addition to cytotoxicity and genotoxicity, it is noteworthy that the copper oxide nanoparticles also induce neurotoxicity and hepatoxicity [203]. Bulcke and Dringen [204] examined the toxicity of copper oxide nanoparticles towards astrocytes in the brain and revealed that the nanoparticles rapidly undergo endocytosismediated accumulation in astrocytes, which increases cellular copper content, ROS production, reduces cell viability, and causes diseases due to metabolic disturbances in brain copper balance [205]. All these studies stand as evidence for the enhanced cytotoxicity of copper oxide nanoparticles and emphasize that size, morphology, dose, and concentration are the significant factors that lead to cytotoxicity. Furthermore, the mechanism of cytotoxicity involves the disintegration into its ionic states; metal ion accumulates in the cells, leading to oxidative stress and lipid peroxidation. In certain cases, the copper ions act as heavy metals [205] and exhibit trojan horse-like mechanism and bind with cell organelles including genetic material and inhibit cell development.

4.4. Zinc Oxide Nanoparticles. Zinc oxide nanoparticles are the most common nanosized metal oxides that are extensively utilized as anticancer agents [206]. They also exhibit enhanced antimicrobial activity, similar to copper oxide nanoparticles [207]. The microbial inhibition ability of zinc oxide nanoparticles is used to fabricate antimicrobial food packages [208], textiles [209], cotton fabric [210], and paints [211]. Moreover, the exclusive anticancer activity of zinc oxide nanoparticles enables them to be useful as nanomedicine [212], nanocarrier of cancer drugs, and optical imaging materials [213]. The zinc oxide nanoparticles also exhibited toxic reactions towards normal, healthy cells, similar to other nanosized metal oxides. However, they are less toxic compared to other metal oxide nanoparticles [214]. Kao et al. [215] evaluated the toxicity of zinc oxide nanoparticles in broncho-alveolar lavage and white blood cells. The result shows that the nanoparticles interfere with the homeostasis of zinc ions present in the body fluid. The disintegration of zinc oxide nanoparticles led to an increase in the zinc ions which eventually causes dysfunction of mitochondria, activation of caspase and apoptosis of cells [215]. Similarly, Sharma et al. [47] examined the in vitro cytotoxicity of zinc oxide nanoparticles towards human HepG2 liver cells. The result demonstrated that the nanoparticles exhibited apoptotic and genotoxic mediated toxicity towards liver cells. They proved that the genotoxicity is due to the damages in DNA and apoptotic toxicity is due to the ROS triggered mitochondrial damage [47]. Furthermore, Heng et al. [216] evaluated the cytotoxicity of spherical and sheet-shaped zinc oxide nanoparticles towards RAW-264.7 mouse cells, BEAS-2B human cells, and primary bone marrow-derived dendritic mouse culture cells. Both the shapes of zinc oxide nanoparticles increased the release of ROS, upregulated the expression of CD80, CD86, and 
released pro-inflammatory cytokines such as IL- 6 and TNF$\alpha$ which inhibits the growth of cells [216]. Likewise, Valdiglesias et al. [217] also proved that zinc oxide nanoparticles induce cyto- and genotoxicity in neurons which they proved by using SHSY5Y human neuronal cells. They emphasized that the nanoparticle did not enter into the cells and toxicity was due to the presence of nanoparticles in the medium, which lead to cell cycle alterations, apoptosis, micronuclei production, H2AX phosphorylation, and DNA damage mediated cyto- and genotoxicity. Furthermore, they added that the toxicity is dose- and time-dependent, whereas free zinc ions from the nanoparticles are not responsible for cytotoxicity in neuronal cells [217]. Several studies also reported the cytotoxicity of zinc oxide nanoparticles towards rat retinal ganglion cells [218], human epidermal cells [219], human nasal mucosa cells [220], murine macrophages [221], and human bronchial epithelial cells [222].

Recently, $\mathrm{Ng}$ et al. [223] evaluated the toxicity of zinc oxide nanoparticles using MRC5 human lung fibroblasts as an in vitro model and Drosophila melanogaster (fruit fly) as the in vivo model. The in vitro studies' result showed that zinc oxide nanoparticles triggered the extracellular secretion of lactate dehydrogenase, which indicates cellular damage and decreased lung cell viability. Furthermore, the presence of DNA damage-inducible transcript (DDIT3) and endoplasmic reticulum to nucleus signaling 1 (ERN1) genes revealed the generation of ROS in the lung cells after nanosized zinc oxide exposure. The in vivo studies also showed that the nanosized zinc oxides are lethal to $D$. melanogaster by releasing ROS, which was indicated by the presence of nuclear factor E2-related factor 2 (Nrf2) [223]. Likewise, Pati et al. [224] reported that the zinc oxide nanoparticles exhibited genotoxic, cytotoxic, clastogenic, and actin depolymerization effects by inducing ROS-mediated oxidative stress responses towards macrophages of mice. In addition, they examined their histopathological effects on adult mice, which revealed that these nanoparticles are highly toxic and lead to severe inflammation and damage to the liver, lungs, and kidneys [224]. Moreover, Abdelmonem et al. [225] synthesized zinc oxide nanoparticles with the same sizes and different surface charges by coating amphiphilic polymers such as poly (isobutylene-alt-maleic anhydride)-graft-dodecyl, mercaptoundecanoic acid, and L-arginine. They examined their in vitro cytotoxicity and uptake of these nanoparticles towards 3T3 fibroblasts and HeLa cells and the result showed that the positively charged arginine-capped nanoparticles facilitate agglomeration internalization into the cells. Thus, they proved that the surface charge of zinc oxide nanoparticles is highly significant in determining their toxicity towards normal cells [225].

4.5. Iron Oxide Nanoparticles. Iron oxide nanoparticles are unique metal oxides that possess magnetic as well as biomedical properties along with their enhanced biocompatibility, bioavailability, and bioactivity [226]. The superparamagnetic property of iron oxide nanoparticles makes them an essential material in the magnetically targeted delivery system for the treatment of cancer [227]. They also possess enhanced antimicrobial properties against bacteria, fungi, algae, and viruses, similar to other metal oxides; however, the mechanism of action is different from other nanosized metal oxides [228-231]. Several pieces of literature also reported that the combination of silver and iron oxide nanoparticles as nanocomposites possess exclusive and unique antimicrobial activities [232]. Even though iron oxide nanoparticles are used in biomedical applications, numerous reports showed that they also exhibit toxicity towards normal healthy cells. Singh et al. [233] reported that the superparamagnetic iron oxide nanoparticles (SPIONs) exhibited cytotoxicity via subtle cellular perturbation such as actin cytoskeleton modulation, gene expression profile alteration, iron homeostasis disturbance, impaired alterations in signaling pathways, cell regulation, DNA damage, and oxidative stress [233]. Similarly, different magnetic nanoparticles such as dextran-coated Endorem, carboxydextran-coated Resovist, lipid-coated magnetoliposomes, and citrate-coated iron oxide particles are evaluated to test their cytotoxicity against C17.2 neural progenitor cells, PC12 rat pheochromocytoma cells, and human blood outgrowth endothelial cells. The results revealed that only lipid-coated magnetoliposomes can internalize at high concentration into all the cell lines which can exhibit enhanced magnetic resonance imaging (MRI) properties [234]. Likewise, Petri-Fink et al. [235] examined the cytotoxicity of SPIONs coated with polyvinyl alcohol (PVA), vinyl alcohol/vinyl amine copolymer (A-PVA), and polyethyleneimine (PEI) towards HeLa cells. The result revealed that A-PVA coated nanoparticles showed good cell viability, compared to others. The study also shows that cytotoxicity is dependent on the colloidal stability in cell media and cellular uptake of the magnetic nanoparticles [235].

In recent times, Valdiglesias et al. [236] reviewed literature and reported the effects of iron oxide nanoparticles on healthy, normal human cells. The article emphasized that the magnetic nanoparticles are highly cytotoxic, genotoxic, developmental toxic, and neurotoxic among humans during short-term exposure and further studies are required to evaluate their long-term exposure effects [236]. In addition, Magdolenova et al. [237] evaluated the effects of surface coatings over iron oxide nanoparticles such as oleate using human lymphoblastoid TK6 cells and primary human blood cells. The result revealed that the surface-coated iron oxide nanoparticles altered their behavior and cellular uptake, and helped them to exhibit dose-dependent cytotoxicity and genotoxicity via DNA damage [237]. Similarly, Valdiglesias et al. [142] examined the toxic mechanism of iron oxide nanoparticles by analyzing several works of literature and reported that factors such as surface coating, dose, size, exposure time, and type of cells are significant to induce cytotoxicity. Furthermore, they conveyed via in vivo studies that these magnetic nanoparticles possess the ability to get distributed to different organs and tissues, especially cross the blood-brain barrier in the brain, and lead to acute toxicity, immunotoxicity, reproductive toxicity, genotoxicity, and neurotoxicity [142]. 
4.6. Aluminium Oxide Nanoparticles. Aluminum oxide or alumina nanoparticles are commonly used in biosensors [238], and certain biomedical applications. They are also used as antimicrobial agents, for bioimaging [239], and as anticancer nanomedicine. There are several reports available which showcased the toxicity of alumina nanoparticles towards various microbes [240] and cancer cells [241]. However, there are some literatures that report alumina nanoparticles as toxic to normal human cells. The trend in the research to evaluate the cytotoxicity of alumina nanoparticles has been increasing only in recent times. Pakrashi et al. [242] revealed the cytotoxicity of alumina nanoparticles towards freshwater algal isolate at a low concentration of exposure. Radziun et al. [243] assessed the cytotoxicity of alumina nanoparticles towards L929 murine fibroblasts and normal BJ human skin fibroblasts cells, which revealed that the alumina nanoparticles are nontoxic to these mammalian cells. Similarly, Yoon et al. [244] investigated the cytotoxicity of alumina nanoparticles for concentrations of $25-200 \mu \mathrm{g} / \mathrm{ml}$ and an incubation time of $0-72 \mathrm{~h}$ using THP-1 floating cells and adherent cells such as A549, 293, and J774A.1. The results emphasized that cytotoxicity depends on the dose, time of exposure, agglomeration, sedimentation, and enhanced cellular uptake [244]. Likewise, Lin et al. [245] evaluated the cytotoxicity of 13 and $22 \mathrm{~nm}$ sized alumina nanoparticles using cultured human bronchoalveolar A549 carcinoma-derived cells and revealed that they are highly toxic than titanium dioxide and less toxic than cerium oxide nanoparticles via alteration in the cell membrane potential, surface chemistry, and exposure duration. In addition, Kim et al. [246] demonstrated that the alumina nanoparticles induce genotoxicity towards BEAS-2B mammalian cell lines.

Recently, More et al. [247] investigated the cytotoxicity of surface-engineered mesoporous alumina nanoparticles synthesized by sol-gel method using cetyl trimethyl ammonium bromide (CTAB). The result showed that the nanoparticles are highly stable up to $24 \mathrm{~h}$ and are less toxic towards Chinese Hamster Ovary (CHO) cells [247]. The reduced toxicity may be due to the enhanced protein adsorption ability [241], especially human plasma proteins [248]. Moreover, Rajiv et al. [249] evaluated the cytotoxicity and genotoxicity of cobalt, iron, silicon, and aluminum oxide nanoparticles towards human lymphocyte cell lines. The result revealed dosedependent toxicity of all these metal oxides, where alumina nanoparticles exhibited the least oxidative stress-mediated DNA damage, compared to other metal oxide nanoparticles [249]. Another study by Asztemborska [250] evaluated and confirmed the toxicity of alumina nanoparticles towards plants via environmental transformation and bioaccumulation. In addition, it was reported that the low-dimensional alumina nanoparticles are highly toxic towards L 929 mouse fibroblast and Neuro-2a Mus musculus brain neuroblastoma cell lines via ROS production and oxidative stress.

\section{Conclusion}

Nanoparticles have found wide biomedical application due to their physicochemical and behavioral uniqueness, although concerns over their toxic effects in the biological system are now drawing the attention of the global health community. This necessitates the importance of the study and the understanding of the effects based on the cellular and molecular mechanisms by which they cause these effects. Some identified toxic mechanisms are through the induction of ROS, cytotoxicity to cells, and genotoxic and neurotoxic effects. This toxic effect depends on the type of nanoparticles, the size, surface area, shape, aspect ratio, surface coating, crystallinity, dissolution, and agglomeration. For instance, it was reported that smaller nanoparticles tend to have greater acute toxicities in animal models. It was also found that the shape or crystallinity of a nanoparticle could influence its toxicity. At this point, it is important that the toxic effects of nanoparticles be considered when synthesizing nanoparticles. Their size, shape, and other key features should be varied in order to ascertain those that work best without causing adverse effects. The consideration of the toxic effects of nanoparticles will open a new page for the synthesis of safer and more effective nanoparticles.

\section{Data Availability}

No data were used to support this study.

\section{Conflicts of Interest}

The authors declare no conflicts of interest.

\section{Acknowledgments}

CE, KCP, ENO, and CGI are thankful to the World Bank, University of Port Harcourt, National Universities Commission, and Association of African Universities for their commitment in encouraging research in the area of public health. JK thanks the Deanship of Scientific Research at Majmaah University for supporting this study.

\section{References}

[1] F. H. Farah, "Nanocarriers as delivery systems for therapeutics agents," International Journal of Pharmaceutical Sciences and Research, vol. 10, pp. 3487-3507, 2019.

[2] X. Zhu, C. Vo, M. Taylor, and B. R. Smith, "Non-spherical micro- and nanoparticles in nanomedicine," Materials Horizons, vol. 6, no. 6, pp. 1094-1121, 2019.

[3] P. Chen, H. Wang, M. He, B. Chen, B. Yang, and B. Hu, "Size-dependent cytotoxicity study of $\mathrm{ZnO}$ nanoparticles in HepG2 cells," Ecotoxicology and Environmental Safety, vol. 171, pp. 337-346, 2019.

[4] C. Renero-Lecuna, N. Iturrioz-Rodríguez, E. GonzálezLavado et al., "Effect of size, shape, and composition on the interaction of different nanomaterials with HeLa cells," Journal of Nanomaterials, vol. 2019, Article ID 7518482, 11 pages, 2019. 
[5] S. Chaicherd, M. C. Killingsworth, and D. Pissuwan, "Toxicity of gold nanoparticles in a commercial dietary supplement drink on connective tissue fibroblast cells," SN Applied Sciences, vol. 1, no. 4, p. 336, 2019.

[6] J. Jeevanandam, Y. S. Chan, and M. K. Danquah, "Biosynthesis of metal and metal oxide nanoparticles," ChemBioEng Reviews, vol. 3, no. 2, pp. 55-67, 2016.

[7] S. Naz, A. Gul, and M. Zia, "Toxicity of copper oxide nanoparticles: a review study," IET Nanobiotechnology, vol. 14, no. 1, pp. 1-13, 2020.

[8] S. Roy, R. Sadhukhan, U. Ghosh, and T. K. Das, "Interaction studies between biosynthesized silver nanoparticle with calf thymus DNA and cytotoxicity of silver nanoparticles," Spectrochimica Acta Part A: Molecular and Biomolecular Spectroscopy, vol. 141, pp. 176-184, 2015.

[9] H. J. Johnston, G. Hutchison, F. M. Christensen, S. Peters, S. Hankin, and V. Stone, "A review of the in vivo and in vitro toxicity of silver and gold particulates: particle attributes and biological mechanisms responsible for the observed toxicity," Critical Reviews in Toxicology, vol. 40, no. 4, pp. 328-346, 2010.

[10] G. Oberdörster, E. Oberdörster, and J. Oberdörster, "Nanotoxicology: an emerging discipline evolving from studies of ultrafine particles," Environmental Health Perspectives, vol. 113, no. 7, pp. 823-839, 2005.

[11] Y.-M. Cho, Y. Mizuta, J.-i. Akagi, T. Toyoda, M. Sone, and K. Ogawa, "Size-dependent acute toxicity of silver nanoparticles in mice," Journal of Toxicologic Pathology, vol. 31, no. 1, pp. 73-80, 2018.

[12] Z. Du, D. Zhao, L. Jing et al., "Cardiovascular toxicity of different sizes amorphous silica nanoparticles in rats after intratracheal instillation," Cardiovascular Toxicology, vol. 13, no. 3, pp. 194-207, 2013.

[13] H. M. Braakhuis, I. Gosens, P. Krystek et al., "Particle size dependent deposition and pulmonary inflammation after short-term inhalation of silver nanoparticles," Particle and Fibre Toxicology, vol. 11, pp. 49-16, 2014.

[14] C. Lopez-Chaves, J. Soto-Alvaredo, M. Montes-Bayon, J. Bettmer, J. Llopis, and C. Sanchez-Gonzalez, "Gold nanoparticles: distribution, bioaccumulation and toxicity. In vitro and in vivo studies," Nanomedicine: Nanotechnology, Biology and Medicine, vol. 14, no. 1, pp. 1-12, 2018.

[15] E. Fröhlich and E. Roblegg, "Models for oral uptake of nanoparticles in consumer products," Toxicology, vol. 291, no. 1-3, pp. 10-17, 2012.

[16] P. Jani, G. W. Halbert, J. Langridge, and A. T. Florence, "Nanoparticle uptake by the rat gastrointestinal mucosa: quantitation and particle size dependency," The Journal of Pharmacy and Pharmacology, vol. 42, pp. 821-826, 1990.

[17] S. Kim and D.-Y. Ryu, "Silver nanoparticle-induced oxidative stress, genotoxicity and apoptosis in cultured cells and animal tissues," Journal of Applied Toxicology, vol. 33, no. 2, pp. 78-89, 2013.

[18] E. A. Morsy, A. M. Hussien, M. A. Ibrahim, K. Y. Farroh, and E. I. Hassanen, "Cytotoxicity and genotoxicity of copper oxide nanoparticles in chickens," Biological Trace Element Research, 2021.

[19] R. Bacchetta, N. Santo, I. Valenti, D. Maggioni, M. Longhi, and P. Tremolada, "Comparative toxicity of three differently shaped carbon nanomaterials on Daphnia magna: does a shape effect exist?" Nanotoxicology, vol. 12, no. 3, pp. 201-223, 2018.

[20] N. B. Abramenko, T. B. Demidova, E. V. Abkhalimov, B. G. Ershov, E. Y. Krysanov, and L. M. Kustov, "Ecotoxicity of different-shaped silver nanoparticles: case of zebrafish embryos," Journal of Hazardous Materials, vol. 347, pp. 89-94, 2018.

[21] C. Carnovale, G. Bryant, R. Shukla, and V. Bansal, "Identifying trends in gold nanoparticle toxicity and uptake: size, shape, capping ligand, and biological corona," ACS Omega, vol. 4, no. 1, pp. 242-256, 2019.

[22] H. Zhou, X. Gong, H. Lin et al., "Gold nanoparticles impair autophagy flux through shape-dependent endocytosis and lysosomal dysfunction," Journal of Materials Chemistry B, vol. 6, no. 48, pp. 8127-8136, 2018.

[23] K. P. Steckiewicz, E. Barcinska, A. Malankowska et al., "Impact of gold nanoparticles shape on their cytotoxicity against human osteoblast and osteosarcoma in in vitro model. Evaluation of the safety of use and anti-cancer potential," Journal of Materials Science: Materials in Medicine, vol. 30, no. 2, p. 22, 2019.

[24] S. E. A. Gratton, P. A. Ropp, P. D. Pohlhaus et al., "The effect of particle design on cellular internalization pathways," Proceedings of the National Academy of Sciences, vol. 105, no. 33, pp. 11613-11618, 2008.

[25] X. Huang, L. Li, T. Liu et al., "The shape effect of mesoporous silica nanoparticles on biodistribution, clearance, and biocompatibility in vivo," ACS Nano, vol. 5, no. 7, pp. 5390-5399, 2011.

[26] W. Li, X. Zhang, X. Hao, J. Jie, B. Tian, and X. Zhang, "Shape design of high drug payload nanoparticles for more effective cancer therapy," Chemical Communications, vol. 49, no. 93, pp. 10989-10991, 2013.

[27] M. Lippmann, "Effects of fiber characteristics on lung deposition, retention, and disease," Environmental Health Perspectives, vol. 88, pp. 311-317, 1990.

[28] J. Muller, F. Huaux, N. Moreau et al., "Respiratory toxicity of multi-wall carbon nanotubes," Toxicology and Applied Pharmacology, vol. 207, no. 3, pp. 221-231, 2005.

[29] L. Li, T. Liu, C. Fu, L. Tan, X. Meng, and H. Liu, "Biodistribution, excretion, and toxicity of mesoporous silica nanoparticles after oral administration depend on their shape," Nanomedicine: Nanotechnology, Biology and Medicine, vol. 11, no. 8, pp. 1915-1924, 2015.

[30] Y.-K. Lai, Q. Wang, J.-Y. Huang et al., " $\mathrm{TiO}_{2}$ nanotube platforms for smart drug delivery: a review," International Journal of Nanomedicine, vol. 11, pp. 4819-4834, 2016.

[31] P. O. Andersson, C. Lejon, B. Ekstrand-Hammarström et al., "Polymorph- and size-dependent uptake and toxicity of $\mathrm{TiO}_{2}$ nanoparticles in living lung epithelial cells," Small, vol. 7, no. 4, pp. 514-523, 2011.

[32] B. Xu, M. A. Malvindi, V. De Matteis et al., "Toxicity assessment of silica coated iron oxide nanoparticles and biocompatibility improvement by surface engineering," PLoS One, vol. 9, Article ID e85835, 2014.

[33] Q. Feng, Y. Liu, J. Huang, K. Chen, J. Huang, and K. Xiao, "Uptake, distribution, clearance, and toxicity of iron oxide nanoparticles with different sizes and coatings," Scientific Reports, vol. 8, no. 1, p. 2082, 2018.

[34] S. K. Misra, A. Dybowska, D. Berhanu, S. N. Luoma, and E. Valsami-Jones, "The complexity of nanoparticle dissolution and its importance in nanotoxicological studies," Science of the Total Environment, vol. 438, pp. 225-232, 2012.

[35] C. S. S. R. Kumar, J. Hormes, and C. Leuschner, Nanofabrication towards Biomedical Applications: Techniques, Tools, Applications, and Impact, Wiley-VCH Verlag $\mathrm{GmbH}$ \& Co. KGaA, Weinheim, Germany, 2005. 
[36] C. Bantz, O. Koshkina, T. Lang et al., "The surface properties of nanoparticles determine the agglomeration state and the size of the particles under physiological conditions," Beilstein Journal of Nanotechnology, vol. 5, pp. 1774-1786, 2014.

[37] P. Wick, P. Manser, L. Limbach et al., "The degree and kind of agglomeration affect carbon nanotube cytotoxicity," Toxicology Letters, vol. 168, no. 2, pp. 121-131, 2007.

[38] J. M. Zook, R. I. MacCuspie, L. E. Locascio, M. D. Halter, and J. T. Elliott, "Stable nanoparticle aggregates/agglomerates of different sizes and the effect of their size on hemolytic cytotoxicity," Nanotoxicology, vol. 5, no. 4, pp. 517-530, 2010.

[39] C. Egbuna and J. C. Ifemeje, "Oxidative stress and nutrition," Tropical Journal of Applied Natural Sciences, vol. 2, no. 1, pp. 110-116, 2017.

[40] J. Ifemeje, S. Udedi, A. Okechukwu et al., "Determination of total protein, superoxide dismutase, catalase activity and lipid peroxidation in soil macro-fauna (earthworm) from Onitsha municipal open waste dump," Journal of Scientific Research and Reports, vol. 6, no. 5, pp. 394-403, 2015.

[41] C. Egbuna, S. Kumar, J. Ifemeje, and J. Kurhekar, "Pharmacognosy, nanomedicine, and contemporary issues," in Phytochemistry, C. Egbuna, Ed., pp. 131-146, Apple Academic Press, New York, NY, USA, 2019.

[42] J. C. Ifemeje, J. T. Gbolakoro, J. T. Gbolakoro, and V. N. Arazu, "Comparative study of antioxidant properties and free radical scavenging capacity of Annona muricata and citrus," Tropical Journal of Applied Natural Sciences, vol. 2, no. 2, pp. 135-140, 2018.

[43] J. K. Tee, C. N. Ong, B. H. Bay, H. K. Ho, and D. T. Leong, "Oxidative stress by inorganic nanoparticles," Wiley Interdisciplinary Reviews: Nanomedicine and Nanobiotechnology, vol. 8, no. 3, pp. 414-438, 2016.

[44] A. Nel, T. Xia, L. Madler, and N. Li, "Toxic potential of materials at the nanolevel," Science, vol. 311, no. 5761, pp. 622-627, 2006.

[45] D. A. M. Kheirallah, L. M. El-Samad, and A. M. AbdelMoneim, "DNA damage and ovarian ultrastructural lesions induced by nickel oxide nano-particles in Blaps polycresta (Coleoptera: tenebrionidae)," Science of the Total Environment, vol. 753, p. 141743, 2021.

[46] A. Kołodziejczak-Radzimska and T. Jesionowski, "Zinc oxide-from synthesis to application: a review," Materials, vol. 7, pp. 2833-2881, 2014.

[47] V. Sharma, D. Anderson, and A. Dhawan, "Zinc oxide nanoparticles induce oxidative DNA damage and ROStriggered mitochondria mediated apoptosis in human liver cells (HepG2)," Apoptosis, vol. 17, no. 8, pp. 852-870, 2012.

[48] J. Wang, X. Deng, F. Zhang, D. Chen, and W. Ding, "ZnO nanoparticle-induced oxidative stress triggers apoptosis by activating JNK signaling pathway in cultured primary astrocytes," Nanoscale Research Letters, vol. 9, no. 1, p. 117, 2014.

[49] J. Hou, H. Liu, S. Zhang et al., "Mechanism of toxic effects of Nano-ZnO on cell cycle of zebrafish (Danio rerio)," Chemosphere, vol. 229, pp. 206-213, 2019.

[50] T. Vangijzegem, D. Stanicki, and S. Laurent, "Magnetic iron oxide nanoparticles for drug delivery: applications and characteristics," Expert Opinion on Drug Delivery, vol. 16, no. 1, pp. 69-78, 2018.

[51] M. Mahmoudi, M. A. Shokrgozar, S. Sardari et al., "Irreversible changes in protein conformation due to interaction with superparamagnetic iron oxide nanoparticles," Nanoscale, vol. 3, pp. 1127-1138, 2011.
[52] S. Laurent, A. A. Saei, S. Behzadi, A. Panahifar, and M. Mahmoudi, "Superparamagnetic iron oxide nanoparticles for delivery of therapeutic agents: opportunities and challenges," Expert Opinion on Drug Delivery, vol. 11, no. 9, pp. 1449-1470, 2014.

[53] V. S. Radhakrishnan, S. P. Dwivedi, M. H. Siddiqui, and T. Prasad, "In vitro studies on oxidative stress-independent, Ag nanoparticles-induced cell toxicity of Candida albicans, an opportunistic pathogen," International Journal of Nanomedicine, vol. 13, pp. 91-96, 2018.

[54] P. Kovvuru, P. E. Mancilla, A. B. Shirode, T. M. Murray, T. J. Begley, and R. Reliene, "Oral ingestion of silver nanoparticles induces genomic instability and DNA damage in multiple tissues," Nanotoxicology, vol. 9, no. 2, pp. 162-171, 2015.

[55] M. I. Setyawati, X. Yuan, J. Xie, and D. T. Leong, "The influence of lysosomal stability of silver nanomaterials on their toxicity to human cells," Biomaterials, vol. 35, no. 25, pp. 6707-6715, 2014.

[56] M. Enea, E. Pereira, M. Peixoto de Almeida, A. M. Araújo, M. D. L. Bastos, and H. Carmo, "Gold nanoparticles induce oxidative stress and apoptosis in human kidney cells," Nanomaterials, vol. 10, no. 5, p. 995, 2020.

[57] D. Mateo, P. Morales, A. Ávalos, and A. I. Haza, "Oxidative stress contributes to gold nanoparticle-induced cytotoxicity in human tumor cells," Toxicology Mechanisms and Methods, vol. 24, no. 3, pp. 161-172, 2014.

[58] M. Ahamed, M. J. Akhtar, M. A. M. Khan, S. A. Alrokayan, and H. A. Alhadlaq, "Oxidative stress mediated cytotoxicity and apoptosis response of bismuth oxide $\left(\mathrm{Bi}_{2} \mathrm{O}_{3}\right)$ nanoparticles in human breast cancer (MCF-7) cells," Chemosphere, vol. 216, pp. 823-831, 2019.

[59] D. Singh, S. Singh, J. Sahu, S. Srivastava, and M. R. Singh, "Ceramic nanoparticles: recompense, cellular uptake and toxicity concerns," Artificial Cells, Nanomedicine, and Biotechnology, vol. 44, no. 1, pp. 401-409, 2014.

[60] C. Guo, Y. Xia, P. Niu et al., "Silica nanoparticles induce oxidative stress, inflammation, and endothelial dysfunction in vitro via activation of the MAPK/Nrf2 pathway and nuclear factor- $\kappa \mathrm{B}$ signaling," International Journal of Nanomedicine, vol. 10, pp. 1463-1477, 2015.

[61] A. A. Shvedova, A. Pietroiusti, B. Fadeel, and V. E. Kagan, "Mechanisms of carbon nanotube-induced toxicity: focus on oxidative stress," Toxicology and Applied Pharmacology, vol. 261, no. 2, pp. 121-133, 2012.

[62] J. Jiang, G. Oberdörster, A. Elder, R. Gelein, P. Mercer, and P. Biswas, "Does nanoparticle activity depend upon size and crystal phase?" Nanotoxicology, vol. 2, no. 1, pp. 33-42, 2009.

[63] J. H. Lee, J. E. Ju, B. I. Kim et al., "Rod-shaped iron oxide nanoparticles are more toxic than sphere-shaped nanoparticles to murine macrophage cells," Environmental Toxicology and Chemistry, vol. 33, no. 12, pp. 2759-2766, 2014.

[64] V. Forest, L. Leclerc, J.-F. Hochepied, A. Trouvé, G. Sarry, and J. Pourchez, "Impact of cerium oxide nanoparticles shape on their in vitro cellular toxicity," Toxicology in Vitro, vol. 38, pp. 136-141, 2017.

[65] W. Kai, X. Xiaojun, P. Ximing, H. Zhenqing, and Z. Qiqing, "Cytotoxic effects and the mechanism of three types of magnetic nanoparticles on human hepatoma BEL-7402 cells," Nanoscale Research Letters, vol. 6, no. 1, p. 480, 2011.

[66] M. Baek, M. K. Kim, H. J. Cho et al., "Factors influencing the cytotoxicity of zinc oxide nanoparticles: particle size and surface charge," Journal of Physics: Conference Series, vol. 304, Article ID 012044, 2011. 
[67] C. C. Chusuei, C.-H. Wu, S. Mallavarapu et al., "Cytotoxicity in the age of nano: the role of fourth period transition metal oxide nanoparticle physicochemical properties," ChemicoBiological Interactions, vol. 206, no. 2, pp. 319-326, 2013.

[68] G. Thiagarajan, K. Greish, and H. Ghandehari, "Charge affects the oral toxicity of poly(amidoamine) dendrimers," European Journal of Pharmaceutics and Biopharmaceutics, vol. 84, no. 2, pp. 330-334, 2013.

[69] H.-T. Chen, M. F. Neerman, A. R. Parrish, and E. E. Simanek, "Cytotoxicity, hemolysis, and acute in vivo toxicity of dendrimers based on melamine, candidate vehicles for drug delivery," Journal of the American Chemical Society, vol. 126, no. 32, pp. 10044-10048, 2004.

[70] D. Pandita, N. Poonia, S. Kumar, V. Lather, and K. Madaan, "Dendrimers in drug delivery and targeting: drug-dendrimer interactions and toxicity issues," Journal of Pharmacy and Bioallied Sciences, vol. 6, no. 3, pp. 139-150, 2014.

[71] J.-H. Lee, K. E. Cha, M. S. Kim et al., "Nanosized polyamidoamine (PAMAM) dendrimer-induced apoptosis mediated by mitochondrial dysfunction," Toxicology Letters, vol. 190, no. 2, pp. 202-207, 2009.

[72] Y.-W. Huang, M. Cambre, and H.-J. Lee, "The toxicity of nanoparticles depends on multiple molecular and physicochemical mechanisms," International Journal of Molecular Sciences, vol. 18, no. 12, p. 2702, 2017.

[73] G. E. Kass and S. Orrenius, "Calcium signaling and cytotoxicity," Environmental Health Perspectives, vol. 107, no. 1, pp. 25-35, 1999.

[74] H.-J. Wang, A. C. Growcock, T.-H. Tang, J. O’Hara, Y.-W. Huang, and R. S. Aronstam, "Zinc oxide nanoparticle disruption of store-operated calcium entry in a muscarinic receptor signaling pathway," Toxicology in Vitro, vol. 24, no. 7, pp. 1953-1961, 2010.

[75] X. Lai, Y. Wei, H. Zhao et al., "The effect of $\mathrm{Fe}_{2} \mathrm{O}_{3}$ and $\mathrm{ZnO}$ nanoparticles on cytotoxicity and glucose metabolism in lung epithelial cells," Journal of Applied Toxicology, vol. 35, no. 6, pp. 651-664, 2015.

[76] L. Li, N. Ma, H. Zhou et al., "Zinc oxide nanoparticles-induced epigenetic change and G2/M arrest are associated with apoptosis in human epidermal keratinocytes," International Journal of Nanomedicine, vol. 11, pp. 3859-3874, 2016.

[77] J. Wu, J. Sun, and Y. Xue, "Involvement of JNK and P53 activation in G2/M cell cycle arrest and apoptosis induced by titanium dioxide nanoparticles in neuron cells," Toxicology Letters, vol. 199, no. 3, pp. 269-276, 2010.

[78] Y. Wang, H. Cui, J. Zhou et al., "Cytotoxicity, DNA damage, and apoptosis induced by titanium dioxide nanoparticles in human non-small cell lung cancer A549 cells," Environmental Science and Pollution Research, vol. 22, no. 7, pp. 5519-5530, 2014.

[79] V. S. Periasamy, J. Athinarayanan, and A. A. Alshatwi, "Aluminum oxide nanoparticles alter cell cycle progression through CCND1 and EGRlgene expression in human mesenchymal stem cells," Biotechnology and Applied Biochemistry, vol. 63, no. 3, pp. 320-327, 2016.

[80] S. R. Saptarshi, A. Duschl, and A. L. Lopata, "Interaction of nanoparticles with proteins: relation to bio-reactivity of the nanoparticle," Journal of Nanobiotechnology, vol. 11, no. 1, p. 26, 2013.

[81] Y.-N. Chang, M. Zhang, L. Xia, J. Zhang, and G. Xing, "The toxic effects and mechanisms of $\mathrm{CuO}$ and $\mathrm{ZnO}$ nanoparticles," Materials, vol. 5, no. 12, pp. 2850-2871, 2012.

[82] K. Vermeulen, D. R. Van Bockstaele, and Z. N. Berneman, "The cell cycle: a review of regulation, deregulation and therapeutic targets in cancer," Cell Proliferation, vol. 36, no. 3, pp. 131-149, 2003.

[83] L. Capasso, M. Camatini, and M. Gualtieri, "Nickel oxide nanoparticles induce inflammation and genotoxic effect in lung epithelial cells," Toxicology Letters, vol. 226, no. 1, pp. 28-34, 2014.

[84] C. Luo, Y. Li, L. Yang et al., "Activation of Erk and p53 regulates copper oxide nanoparticle-induced cytotoxicity in keratinocytes and fibroblasts," International Journal of Nanomedicine, vol. 9, pp. 4763-4772, 2014.

[85] X. Gao, Y. Wang, S. Peng et al., "Comparative toxicities of bismuth oxybromide and titanium dioxide exposure on human skin keratinocyte cells," Chemosphere, vol. 135, pp. 83-93, 2015.

[86] N. Hanagata, F. Zhuang, S. Connolly, J. Li, N. Ogawa, and $\mathrm{M}$. Xu, "Molecular responses of human lung epithelial cells to the toxicity of copper oxide nanoparticles inferred from whole genome expression analysis," ACS Nano, vol. 5, no. 12, pp. 9326-9338, 2011.

[87] M. Auffan, J. Rose, J.-Y. Bottero, G. V. Lowry, J.-P. Jolivet, and M. R. Wiesner, "Towards a definition of inorganic nanoparticles from an environmental, health and safety perspective," Nature Nanotechnology, vol. 4, no. 10, pp. 634-641, 2009.

[88] L. Benameur, L. Wei, and A. Botta, "Genotoxicity of nanoparticles," in Encyclopedia of Nanotechnology, B. Bhushan, Ed., pp. 952-962, Springer Netherlands, Dordrecht, Netherlands, 2012.

[89] D. B. Sebastiano and H. Karlsson, Nanomaterials and Genotoxicity-A Literature Review, KEMI The Swedish Chemicals Agency, Stockholm, Sweden, 2016.

[90] E. R. Kisin, A. R. Murray, M. J. Keane et al., "Singlewalled carbon nanotubes: geno- and cytotoxic effects in lung fibroblast V79 cells," Journal of Toxicology and Environmental Health, Part A, vol. 70, no. 24, pp. 20712079, 2007.

[91] A. O. Adiguzel, S. K. Adiguzel, B. Mazmanci, M. Tunçer, and M. A. Mazmanci, "Silver nanoparticle biosynthesis from newly isolated streptomyces genus from soil," Materials Research Express, vol. 5, no. 4, Article ID 045402, 2018.

[92] J. Pandiarajan and S. Balaji, "Genotoxic effect of silver nanoparticles in silk worm Bombyx mori," Austin Journal of Biotechnology \& Bioengineeringis, vol. 5, p. 1096, 2018.

[93] R. Ishwarya, B. Vaseeharan, S. Shanthi et al., "Green synthesized silver nanoparticles: toxicity against Poecilia reticulata fishes and Ceriodaphnia cornuta crustaceans," Journal of Cluster Science, vol. 28, no. 1, pp. 519-527, 2017.

[94] C. Krishnaraj, S. L. Harper, and S.-I. Yun, "In Vivo toxicological assessment of biologically synthesized silver nanoparticles in adult Zebrafish (Danio rerio)," Journal of Hazardous Materials, vol. 301, pp. 480-491, 2016.

[95] Q. Lv, B. Zhang, X. Xing et al., "Biosynthesis of copper nanoparticles using Shewanella loihica PV-4 with antibacterial activity: novel approach and mechanisms investigation," Journal of Hazardous Materials, vol. 347, pp. 141-149, 2018.

[96] K. K. Panda, D. Golari, A. Venugopal et al., "Green synthesized zinc oxide $(\mathrm{ZnO})$ nanoparticles induce oxidative stress and DNA damage in lathyrus sativus L. Root bioassay system," Antioxidants (Basel, Switzerland), vol. 6, no. 2, 2017.

[97] N. Saha and S. Dutta Gupta, "Low-dose toxicity of biogenic silver nanoparticles fabricated by Swertia chirata on root tips and flower buds of Allium cepa," Journal of Hazardous Materials, vol. 330, pp. 18-28, 2017. 
[98] N. R. Abdelsalam, A. Abdel-Megeed, H. M. Ali, M. Z. M. Salem, M. F. A. Al-Hayali, and M. S. Elshikh, "Genotoxicity effects of silver nanoparticles on wheat (Triticum aestivum L.) root tip cells," Ecotoxicology and Environmental Safety, vol. 155, pp. 76-85, 2018.

[99] M. Thiruvengadam, S. Gurunathan, and I.-M. Chung, "Physiological, metabolic, and transcriptional effects of biologically-synthesized silver nanoparticles in turnip (Brassica rapa ssp. rapa L.)," Protoplasma, vol. 252, no. 4, pp. 1031-1046, 2015.

[100] A. A. Shvedova, E. Kisin, A. R. Murray et al., "Inhalation vs. aspiration of single-walled carbon nanotubes in C57BL/6 mice: inflammation, fibrosis, oxidative stress, and mutagenesis," American Journal of Physiology-Lung Cellular and Molecular Physiology, vol. 295, no. 4, pp. L552-L565, 2008.

[101] L. Zhu, D. W. Chang, L. Dai, and Y. Hong, "DNA damage induced by multiwalled carbon nanotubes in mouse embryonic stem cells," Nano Letters, vol. 7, no. 12, pp. 3592-3597, 2007.

[102] R. Landsiedel, M. D. Kapp, M. Schulz, K. Wiench, and F. Oesch, "Genotoxicity investigations on nanomaterials: methods, preparation and characterization of test material, potential artifacts and limitations-many questions, some answers," Mutation Research/Reviews in Mutation Research, vol. 681, no. 2-3, pp. 241-258, 2009.

[103] J. Muller, I. Decordier, P. H. Hoet et al., "Clastogenic and aneugenic effects of multi-wall carbon nanotubes in epithelial cells," Carcinogenesis, vol. 29, no. 2, pp. 427-433, 2008.

[104] M. Ema, S. Masumori, N. Kobayashi et al., "In vivocomet assay of multi-walled carbon nanotubes using lung cells of rats intratracheally instilled," Journal of Applied Toxicology, vol. 33, no. 10, pp. 1053-1060, 2013.

[105] D. Pothmann, S. Simar, D. Schuler et al., "Lung inflammation and lack of genotoxicity in the comet and micronucleus assays of industrial multiwalled carbon nanotubes Graphistrength C100 after a 90-day nose-only inhalation exposure of rats," Particle and Fibre Toxicology, vol. 12, no. 1, p. 21, 2015.

[106] A. K. Patlolla, S. M. Hussain, J. J. Schlager, S. Patlolla, and P. B. Tchounwou, "Comparative study of the clastogenicity of functionalized and nonfunctionalized multiwalled carbon nanotubes in bone marrow cells of Swiss-Webster mice," Environmental Toxicology, vol. 25, no. 6, pp. 608-621, 2010.

[107] A. K. Patlolla, P. K. Patra, M. Flountan, and P. B. Tchounwou, "Cytogenetic evaluation of functionalized single-walled carbon nanotube in mice bone marrow cells," Environmental Toxicology, vol. 31, no. 9, pp. 1091-1102, 2016.

[108] S. W. P. Wijnhoven, W. J. G. M. Peijnenburg, C. A. Herberts et al., "Nano-silver-a review of available data and knowledge gaps in human and environmental risk assessment," Nanotoxicology, vol. 3, no. 2, pp. 109-138, 2009.

[109] T. A. J. Souza, L. P. Franchi, L. R. Rosa, M. A. M. S. da Veiga, and C. S. Takahashi, "Cytotoxicity and genotoxicity of silver nanoparticles of different sizes in CHO-K1 and CHO-XRS5 cell lines," Mutation Research/Genetic Toxicology and Environmental Mutagenesis, vol. 795, pp. 70-83, 2016.

[110] X. Jiang, R. Foldbjerg, T. Miclaus et al., "Multi-platform genotoxicity analysis of silver nanoparticles in the model cell line CHO-K1," Toxicology Letters, vol. 222, no. 1, pp. 55-63, 2013.

[111] P. V. AshaRani, G. Low Kah Mun, M. P. Hande, and S. Valiyaveettil, "Cytotoxicity and genotoxicity of silver nanoparticles in human cells," ACS Nano, vol. 3, no. 2, pp. 279-290, 2008.

[112] G. Joksić, J. Stašić, J. Filipović, A. V. Šobot, and M. Trtica, "Size of silver nanoparticles determines proliferation ability of human circulating lymphocytes in vitro," Toxicology Letters, vol. 247, pp. 29-34, 2016.

[113] A. Huk, E. Izak-Nau, B. Reidy et al., "Is the toxic potential of nanosilver dependent on its size?" Particle and Fibre Toxicology, vol. 11, no. 1, p. 65, 2014.

[114] S. Di Bucchianico, M. R. Fabbrizi, S. Cirillo et al., "Aneuploidogenic effects and DNA oxidation induced in vitro by differently sized gold nanoparticles," International Journal of Nanomedicine, vol. 9, pp. 2191-2204, 2014.

[115] S. Fraga, H. Faria, M. E. Soares et al., "Influence of the surface coating on the cytotoxicity, genotoxicity and uptake of gold nanoparticles in human HepG2 cells," Journal of Applied Toxicology, vol. 33, no. 10, pp. 1111-1119, 2013.

[116] J. J. Li, S.-L. Lo, C.-T. Ng et al., "Genomic instability of gold nanoparticle treated human lung fibroblast cells," Biomaterials, vol. 32, no. 23, pp. 5515-5523, 2011.

[117] S. Di Bucchianico, L. Migliore, P. Marsili, C. Vergari, F. Giammanco, and E. Giorgetti, "Cyto- and genotoxicity assessment of gold nanoparticles obtained by laser ablation in A549 lung adenocarcinoma cells," Journal of Nanoparticle Research, vol. 17, no. 5, p. 213, 2015.

[118] E. Cardoso, G. T. Rezin, E. T. Zanoni et al., "Acute and chronic administration of gold nanoparticles cause DNA damage in the cerebral cortex of adult rats," Mutation Research/Fundamental and Molecular Mechanisms of Mutagenesis, vol. 766-767, pp. 25-30, 2014

[119] S. I. Matsushita, T. Miwa, D. A. Tryk, and A. Fujishima, "New mesostructured porous $\mathrm{TiO}_{2}$ Surface prepared using a two-dimensional array-based template of silica particles," Langmuir, vol. 14, no. 22, pp. 6441-6447, 1998.

[120] H. Wang, J. Feng, G. Liu, B. Chen, Y. Jiang, and Q. Xie, "In vitro and in vivo anti-tumor efficacy of 10-hydroxycamptothecin polymorphic nanoparticle dispersions: shape- and polymorph-dependent cytotoxicity and delivery of 10-hydroxycamptothecin to cancer cells," Nanomedicine: Nanotechnology, Biology and Medicine, vol. 12, no. 4, pp. 881-891, 2016.

[121] H. Zhang, C. Wang, B. Chen, and X. Wang, "Daunorubicin$\mathrm{TiO}_{2}$ nanocomposites as a smart $\mathrm{pH}$-responsive drug delivery system," International Journal of Nanomedicine, vol. 7, pp. 235-242, 2012.

[122] Q. Rahman, M. Lohani, E. Dopp et al., "Evidence that ultrafine titanium dioxide induces micronuclei and apoptosis in Syrian hamster embryo fibroblasts," Environmental Health Perspectives, vol. 110, no. 8, pp. 797-800, 2002.

[123] I. F. Osman, A. Baumgartner, E. Cemeli, J. N. Fletcher, and D. Anderson, "Genotoxicity and cytotoxicity of zinc oxide and titanium dioxide in HEp-2 cells," Nanomedicine, vol. 5, no. 8, pp. 1193-1203, 2010.

[124] S. J. Kang, B. M. Kim, Y. J. Lee, and H. W. Chung, "Titanium dioxide nanoparticles trigger p53-mediated damage response in peripheral blood lymphocytes," Environmental and Molecular Mutagenesis, vol. 49, no. 5, pp. 399-405, 2008.

[125] B. Trouiller, R. Reliene, A. Westbrook, P. Solaimani, and R. H. Schiestl, "Titanium dioxide nanoparticles induce DNA damage and genetic instability in vivo in mice," Cancer Research, vol. 69, no. 22, pp. 8784-8789, 2009.

[126] J. Grigg, A. Tellabati, S. Rhead et al., "DNA damage of macrophages at an air-tissue interface induced by metal 
nanoparticles," Nanotoxicology, vol. 3, no. 4, pp. 348-354, 2009.

[127] S. Kückelhaus, "Magnetoliposome evaluation using cytometry and micronucleus test," European Cells and Materials, vol. 3, pp. 154-155, 2002.

[128] N. Sadeghiani, L. S. Barbosa, L. P. Silva, R. B. Azevedo, P. C. Morais, and Z. G. M. Lacava, "Genotoxicity and inflammatory investigation in mice treated with magnetite nanoparticles surface coated with polyaspartic acid," Journal of Magnetism and Magnetic Materials, vol. 289, pp. 466-468, 2005.

[129] K. Gerloff, C. Albrecht, A. W. Boots, I. Förster, and R. P. F. Schins, "Cytotoxicity and oxidative DNA damage by nanoparticles in human intestinal Caco-2 cells," Nanotoxicology, vol. 3, no. 4, pp. 355-364, 2009.

[130] J. J. Wang, B. J. S. Sanderson, and H. Wang, "Cytotoxicity and genotoxicity of ultrafine crystalline $\mathrm{SiO}_{2}$ particulate in cultured human lymphoblastoid cells," Environmental and Molecular Mutagenesis, vol. 48, no. 2, pp. 151-157, 2007.

[131] C. M. Sayes, K. L. Reed, K. P. Glover et al., "Changing the dose metric for inhalation toxicity studies: short-term study in rats with engineered aerosolized amorphous silica nanoparticles," Inhalation Toxicology, vol. 22, no. 4, pp. 348-354, 2009.

[132] Y. Zeng, Y. Kurokawa, T.-T. Win-Shwe et al., "Effects of PAMAM dendrimers with various surface functional groups and multiple generations on cytotoxicity and neuronal differentiation using human neural progenitor cells," The Journal of Toxicological Sciences, vol. 41, no. 3, pp. 351-370, 2016.

[133] L. G. Costa, C. Pellacani, and M. Guizzetti, "In vitro and alternative approaches to developmental neurotoxicity," in Reproductive and Developmental Toxicology, R. C. Gupta, Ed., pp. 241-253, Academic Press, Cambridge, MA, USA, 2017.

[134] D. Teleanu, C. Chircov, A. Grumezescu, and R. Teleanu, "Neurotoxicity of nanomaterials: an up-to-date overview," Nanomaterials, vol. 9, no. 1, p. 96, 2019.

[135] T.-T. Win-Shwe and H. Fujimaki, "Nanoparticles and neurotoxicity," International Journal of Molecular Sciences, vol. 12, no. 9, pp. 6267-6280, 2011.

[136] D. Shi, G. Mi, and T. J. Webster, "The synthesis, application, and related neurotoxicity of carbon nanotubes," in Neurotoxicity of Nanomaterials and Nanomedicine, X. Jiang and H. Gao, Eds., pp. 259-284, Academic Press, Cambridge, MA, USA, 2017.

[137] B. Gholamine, I. Karimi, A. Salimi, P. Mazdarani, and L. A. Becker, "Neurobehavioral toxicity of carbon nanotubes in mice," Toxicology and Industrial Health, vol. 33, no. 4, pp. 340-350, 2016.

[138] M. F. Rahman, J. Wang, T. A. Patterson et al., "Expression of genes related to oxidative stress in the mouse brain after exposure to silver-25 nanoparticles," Toxicology Letters, vol. 187, no. 1, pp. 15-21, 2009.

[139] B. Song, Y. Zhang, J. Liu, X. Feng, T. Zhou, and L. Shao, "Unraveling the neurotoxicity of titanium dioxide nanoparticles: focusing on molecular mechanisms," Beilstein Journal of Nanotechnology, vol. 7, pp. 645-654, 2016.

[140] T. C. Long, J. Tajuba, P. Sama et al., "Nanosize titanium dioxide stimulates reactive oxygen species in brain microglia and damages neurons in vitro," Environmental Health Perspectives, vol. 115, no. 11, pp. 1631-1637, 2007.

[141] J. Hou, L. Wang, C. Wang et al., "Toxicity and mechanisms of action of titanium dioxide nanoparticles in living organisms," Journal of Environmental Sciences, vol. 75, pp. 40-53, 2019.

[142] V. Valdiglesias, N. Fernández-Bertólez, G. Kiliç et al., "Are iron oxide nanoparticles safe? Current knowledge and future perspectives," Journal of Trace Elements in Medicine and Biology, vol. 38, pp. 53-63, 2016.

[143] Z. Yarjanli, K. Ghaedi, A. Esmaeili, S. Rahgozar, and A. Zarrabi, "Iron oxide nanoparticles may damage to the neural tissue through iron accumulation, oxidative stress, and protein aggregation," BMC Neuroscience, vol. 18, no. 1, p. 51, 2017.

[144] T. R. Pisanic, J. D. Blackwell, V. I. Shubayev, R. R. Fiñones, and S. Jin, "Nanotoxicity of iron oxide nanoparticle internalization in growing neurons," Biomaterials, vol. 28, no. 16, pp. 2572-2581, 2007.

[145] M. F. Kircher, U. Mahmood, R. S. King, R. Weissleder, and L. Josephson, "A multimodal nanoparticle for preoperative magnetic resonance imaging and intraoperative optical brain tumor delineation," Cancer Research, vol. 63, pp. 8122-8125, 2003.

[146] R. You, Y.-S. Ho, C. H.-L. Hung et al., "Silica nanoparticles induce neurodegeneration-like changes in behavior, neuropathology, and affect synapse through MAPK activation," Particle and Fibre Toxicology, vol. 15, no. 1, p. 28, 2018.

[147] M. Zhou, L. Xie, C.-J. Fang et al., "Implications for bloodbrain-barrier permeability, in vitro oxidative stress and neurotoxicity potential induced by mesoporous silica nanoparticles: effects of surface modification," RSC Advances, vol. 6, no. 4, pp. 2800-2809, 2016.

[148] N. Singh, A. Joshi, A. P. Toor, and G. Verma, "Drug delivery: advancements and challenges," in Nanostructures for Drug Delivery, E. Andronescu and A. M. Grumezescu, Eds., pp. 865-886, Elsevier, Amsterdam Netherlands, 2017.

[149] S. Hussain, Z. Y. Yuan, Y. L. Hu, and J. Q. Gao, "Brain localization and neurotoxicity evaluation of polysorbate 80 modified chitosan nanoparticles in rats," PLoS One, vol. 10, Article ID e0134722, 2015.

[150] Y. Zeng, Y. Kurokawa, Q. Zeng et al., "Effects of polyamidoamine dendrimers on a 3-D neurosphere system using human neural progenitor cells," Toxicological Sciences, vol. 152, no. 1, pp. 128-144, 2016.

[151] M. N. Calienni, D. A. Feas, D. E. Igartúa, N. S. Chiaramoni, S. D. V. Alonso, and M. J. Prieto, "Nanotoxicological and teratogenic effects: a linkage between dendrimer surface charge and zebrafish developmental stages," Toxicology and Applied Pharmacology, vol. 337, pp. 1-11, 2017.

[152] M. Rai, A. P. Ingle, S. Bansod, and K. Kon, "Tackling the problem of tuberculosis by nanotechnology," in Nanotechnology in Diagnosis, Treatment and Prophylaxis of Infectious Diseases, M. Rai and K. Kon, Eds., pp. 133-149, Academic Press, Boston, MA, USA, 2015.

[153] W. Debinski, T. Huo, R. F. Barth et al., "Preparation, biodistribution and neurotoxicity of liposomal cisplatin following convection enhanced delivery in normal and F98 glioma bearing rats," PLoS One, vol. 7, Article ID e48752, 2012.

[154] J. Khalili Fard, S. Jafari, and M. A. Eghbal, "A review of molecular mechanisms involved in toxicity of nanoparticles," Advanced Pharmaceutical Bulletin, vol. 5, no. 4, pp. 447-454, 2015.

[155] K. Choi, J. E. Riviere, and N. A. Monteiro-Riviere, "Protein corona modulation of hepatocyte uptake and molecular mechanisms of gold nanoparticle toxicity," Nanotoxicology, vol. 11, no. 1, pp. 64-75, 2016. 
[156] S. Shin, I. Song, and S. Um, "Role of physicochemical properties in nanoparticle toxicity," Nanomaterials, vol. 5, no. 3, pp. 1351-1365, 2015.

[157] R. Shrivastava, P. Kushwaha, Y. C. Bhutia, and S. Flora, "Oxidative stress following exposure to silver and gold nanoparticles in mice," Toxicology and Industrial Health, vol. 32, no. 8, pp. 1391-1404, 2014.

[158] Y. Wang, R. Xia, H. Hu, and T. Peng, "Biosynthesis, characterization and cytotoxicity of gold nanoparticles and their loading with $\mathrm{N}$-acetylcarnosine for cataract treatment," Journal of Photochemistry and Photobiology B: Biology, vol. 187, pp. 180-183, 2018.

[159] A. Rajeshwari, S. Suresh, N. Chandrasekaran, and A. Mukherjee, "Toxicity evaluation of gold nanoparticles using an Allium cepa bioassay," RSC Advances, vol. 6, no. 29, pp. 24000-24009, 2016.

[160] D. Bobo, K. J. Robinson, J. Islam, K. J. Thurecht, and S. R. Corrie, "Nanoparticle-based medicines: a review of FDA-approved materials and clinical trials to date," Pharmaceutical Research, vol. 33, no. 10, pp. 2373-2387, 2016.

[161] E. Priyadarshini and N. Pradhan, "Gold nanoparticles as efficient sensors in colorimetric detection of toxic metal ions: a review," Sensors and Actuators B: Chemical, vol. 238, pp. 888-902, 2017.

[162] M.-C. Senut, Y. Zhang, F. Liu, A. Sen, D. M. Ruden, and G. Mao, "Size-dependent toxicity of gold nanoparticles on human embryonic stem cells and their neural derivatives," Small, vol. 12, no. 5, pp. 631-646, 2016.

[163] S. Mukherjee, S. Sau, D. Madhuri et al., "Green synthesis and characterization of monodispersed gold nanoparticles: toxicity study, delivery of doxorubicin and its bio-distribution in mouse model," Journal of Biomedical Nanotechnology, vol. 12, no. 1, pp. 165-181, 2016.

[164] M.-R. Jo, S.-H. Bae, M.-R. Go, H.-J. Kim, Y.-G. Hwang, and S.-J. Choi, "Toxicity and biokinetics of colloidal gold nanoparticles," Nanomaterials, vol. 5, no. 2, pp. 835-850, 2015.

[165] I. Fratoddi, I. Venditti, C. Cametti, and M. V. Russo, "The puzzle of toxicity of gold nanoparticles: the case-study of HeLa cells," Toxicology Research, vol. 4, no. 4, pp. 796-800, 2015.

[166] M. V. Brundo, R. Pecoraro, F. Marino et al., "Toxicity evaluation of new engineered nanomaterials in Zebrafish," Frontiers in Physiology, vol. 7, p. 130, 2016.

[167] M. Semmler-Behnke, J. Lipka, A. Wenk et al., "Size dependent translocation and fetal accumulation of gold nanoparticles from maternal blood in the rat," Particle and Fibre Toxicology, vol. 11, no. 1, p. 33, 2014.

[168] X.-F. Zhang, Z.-G. Liu, W. Shen, and S. Gurunathan, "Silver nanoparticles: synthesis, characterization, properties, applications, and therapeutic approaches," International Journal of Molecular Sciences, vol. 17, no. 9, p. 1534, 2016.

[169] N. Durán, M. Durán, M. B. de Jesus, A. B. Seabra, W. J. Fávaro, and G. Nakazato, "Silver nanoparticles: a new view on mechanistic aspects on antimicrobial activity," Nanomedicine: Nanotechnology, Biology and Medicine, vol. 12, no. 3, pp. 789-799, 2016

[170] N. Durán, G. Nakazato, and A. B. Seabra, "Antimicrobial activity of biogenic silver nanoparticles, and silver chloride nanoparticles: an overview and comments," Applied Microbiology and Biotechnology, vol. 100, no. 15, pp. 6555-6570, 2016.

[171] K. Venugopal, H. Ahmad, E. Manikandan et al., "The impact of anticancer activity upon Beta vulgaris extract mediated biosynthesized silver nanoparticles (ag-NPs) against human breast (MCF-7), lung (A549) and pharynx (Hep-2) cancer cell lines," Journal of Photochemistry and Photobiology B: Biology, vol. 173, pp. 99-107, 2017.

[172] M. Buttacavoli, N. N. Albanese, G. Di Cara et al., "Anticancer activity of biogenerated silver nanoparticles: an integrated proteomic investigation," Oncotarget, vol. 9, no. 11, pp. 9685-9705, 2018.

[173] M. S. Bethu, V. R. Domdi, V. Tartte, and V. R. Janapala, "Potential anticancer activity of biogenic silver nanoparticles using leaf extract of Rhynchosia suaveolens: an insight into the mechanism," Artificial Cells, Nanomedicine, and Biotechnology, vol. 46, no. 1, pp. 104-114, 2018.

[174] S. Kim, J. E. Choi, J. Choi et al., "Oxidative stress-dependent toxicity of silver nanoparticles in human hepatoma cells," Toxicology in Vitro, vol. 23, no. 6, pp. 1076-1084, 2009.

[175] Y. J. Kim, H. S. Choi, M. K. Song, D. Y. Youk, J. H. Kim, and J. C. Ryu, "Genotoxicity of aluminum oxide $\left(\mathrm{Al}_{2} \mathrm{O}_{3}\right)$ nanoparticle in mammalian cell lines," Molecular and Cellular Toxicology, vol. 5, pp. 172-178, 2009.

[176] M. Ahamed, M. S. AlSalhi, and M. K. J. Siddiqui, "Silver nanoparticle applications and human health," Clinica Chimica Acta, vol. 411, no. 23-24, pp. 1841-1848, 2010.

[177] M. Ahamed, M. A. Siddiqui, M. J. Akhtar, I. Ahmad, A. B. Pant, and H. A. Alhadlaq, "Genotoxic potential of copper oxide nanoparticles in human lung epithelial cells," Biochemical and Biophysical Research Communications, vol. 396, no. 2, pp. 578-583, 2010.

[178] R. de Lima, A. B. Seabra, and N. Durán, "Silver nanoparticles: a brief review of cytotoxicity and genotoxicity of chemically and biogenically synthesized nanoparticles," Journal of Applied Toxicology, vol. 32, no. 11, pp. 867-879, 2012.

[179] S. Gaillet and J.-M. Rouanet, "Silver nanoparticles: their potential toxic effects after oral exposure and underlying mechanisms-a review," Food and Chemical Toxicology, vol. 77, pp. 58-63, 2015.

[180] D. C. Kennedy, H. Qian, V. Gies, and L. Yang, "Human serum albumin stabilizes aqueous silver nanoparticle suspensions and inhibits particle uptake by cells," Environmental Science: Nano, vol. 5, no. 4, pp. 863-867, 2018.

[181] J. N. Smith, D. G. Thomas, H. Jolley et al., "All that is silver is not toxic: silver ion and particle kinetics reveals the role of silver ion aging and dosimetry on the toxicity of silver nanoparticles," Particle and Fibre Toxicology, vol. 15, no. 1, p. 47,2018 .

[182] A. L. McCormack, M. Thiruchelvam, A. B. Manning-Bog et al., "Environmental risk factors and Parkinson's disease: selective degeneration of nigral dopaminergic neurons caused by the herbicide paraquat," Neurobiology of Disease, vol. 10, no. 2, pp. 119-127, 2002.

[183] T. Eggermann, N. Schönherr, E. Meyer et al., "Epigenetic mutations in 11p15 in Silver-Russell syndrome are restricted to the telomeric imprinting domain," Journal of Medical Genetics, vol. 43, pp. 615-616, 2006.

[184] G. Testa, E. Staurenghi, S. Giannelli et al., "A silver lining for 24-hydroxycholesterol in Alzheimer's disease: the involvement of the neuroprotective enzyme sirtuin 1," Redox Biology, vol. 17, pp. 423-431, 2018.

[185] G. Ren, D. Hu, E. W. C. Cheng, M. A. Vargas-Reus, P. Reip, and R. P. Allaker, "Characterisation of copper oxide nanoparticles for antimicrobial applications," International Journal of Antimicrobial Agents, vol. 33, no. 6, pp. 587-590, 2009.

[186] M. Ahamed, H. A. Alhadlaq, M. A. M. Khan, P. Karuppiah, and N. A. Al-Dhabi, "Synthesis, characterization, and 
antimicrobial activity of copper oxide nanoparticles," Journal of Nanomaterials, vol. 2014, Article ID 637858, 4 pages, 2014.

[187] R. Sankar, R. Maheswari, S. Karthik, K. S. Shivashangari, and V. Ravikumar, "Anticancer activity of Ficus religiosa engineered copper oxide nanoparticles," Materials Science and Engineering: C, vol. 44, pp. 234-239, 2014.

[188] O. Perlman, I. S. Weitz, and H. Azhari, "Copper oxide nanoparticles as contrast agents for MRI and ultrasound dual-modality imaging," Physics in Medicine and Biology, vol. 60 , no. 15 , pp. 5767-5783, 2015.

[189] M. Černík and V. V. Thekkae Padil, "Green synthesis of copper oxide nanoparticles using gum karaya as a biotemplate and their antibacterial application," International Journal of Nanomedicine, vol. 8, pp. 889-898, 2013.

[190] D. Devipriya and S. M. Roopan, "Cissus quadrangularis mediated ecofriendly synthesis of copper oxide nanoparticles and its antifungal studies against Aspergillus niger, Aspergillus flavus," Materials Science and Engineering: C, vol. 80, pp. 38-44, 2017.

[191] A. P. Ingle, N. Duran, and M. Rai, "Bioactivity, mechanism of action, and cytotoxicity of copper-based nanoparticles: a review," Applied Microbiology and Biotechnology, vol. 98, no. 3, pp. 1001-1009, 2013.

[192] B. Fahmy and S. A. Cormier, "Copper oxide nanoparticles induce oxidative stress and cytotoxicity in airway epithelial cells," Toxicology in Vitro, vol. 23, no. 7, pp. 1365-1371, 2009.

[193] H. L. Karlsson, P. Cronholm, J. Gustafsson, and L. Möller, "Copper oxide nanoparticles are highly toxic: a comparison between metal oxide nanoparticles and carbon nanotubes," Chemical Research in Toxicology, vol. 21, no. 9, pp. 17261732, 2008.

[194] A. M. Studer, L. K. Limbach, L. Van Duc et al., "Nanoparticle cytotoxicity depends on intracellular solubility: comparison of stabilized copper metal and degradable copper oxide nanoparticles," Toxicology Letters, vol. 197, no. 3, pp. 169-174, 2010.

[195] S. Alarifi, D. Ali, A. Verma, S. Alakhtani, and B. A. Ali, "Cytotoxicity and genotoxicity of copper oxide nanoparticles in human skin keratinocytes cells," International Journal of Toxicology, vol. 32, no. 4, pp. 296-307, 2013.

[196] J. Sun, S. Wang, D. Zhao, F. H. Hun, L. Weng, and H. Liu, "Cytotoxicity, permeability, and inflammation of metal oxide nanoparticles in human cardiac microvascular endothelial cells," Cell Biology and Toxicology, vol. 27, no. 5, pp. 333-342, 2011.

[197] D. Cohen, Y. Soroka, Z. Ma'or et al., "Evaluation of topically applied copper(II) oxide nanoparticle cytotoxicity in human skin organ culture," Toxicology in Vitro, vol. 27, no. 1, pp. 292-298, 2013.

[198] D. H. Atha, H. Wang, E. J. Petersen et al., "Copper oxide nanoparticle mediated DNA damage in terrestrial plant models," Environmental Science \& Technology, vol. 46, no. 3, pp. 1819-1827, 2012.

[199] A. Wongrakpanich, I. A. Mudunkotuwa, S. M. Geary et al., "Size-dependent cytotoxicity of copper oxide nanoparticles in lung epithelial cells," Environmental Science: Nano, vol. 3, no. 2, pp. 365-374, 2016.

[200] M. J. Akhtar, S. Kumar, H. A. Alhadlaq, S. A. Alrokayan, K. M. Abu-Salah, and M. Ahamed, "Dose-dependent genotoxicity of copper oxide nanoparticles stimulated by reactive oxygen species in human lung epithelial cells," Toxicology and Industrial Health, vol. 32, no. 5, pp. 809-821, 2013.
[201] K. Srikanth, E. Pereira, A. C. Duarte, and J. V. Rao, "Evaluation of cytotoxicity, morphological alterations and oxidative stress in Chinook salmon cells exposed to copper oxide nanoparticles," Protoplasma, vol. 253, no. 3, pp. 873-884, 2015.

[202] V. C. Ude, D. M. Brown, L. Viale, N. Kanase, V. Stone, and H. J. Johnston, "Impact of copper oxide nanomaterials on differentiated and undifferentiated Caco-2 intestinal epithelial cells; assessment of cytotoxicity, barrier integrity, cytokine production and nanomaterial penetration," Particle and Fibre Toxicology, vol. 14, no. 1, p. 31, 2017.

[203] Y. Li, Y. Sun, G. Zhang, Z. He, Y. Wang, and J. Cui, "Effects of copper oxide nanoparticles on developing zebrafish embryos and larvae," International Journal of Nanomedicine, vol. 11, pp. 905-918, 2016.

[204] F. Bulcke and R. Dringen, "Handling of copper and copper oxide nanoparticles by astrocytes," Neurochemical Research, vol. 41, no. 1-2, pp. 33-43, 2015.

[205] F. Bulcke, R. Dringen, and I. F. Scheiber, "Neurotoxicity of copper," in Neurotoxicity of Metals, M. Aschner and L. G. Costa, Eds., pp. 313-343, Springer, Cham, Switzerland, 2017.

[206] J. W. Rasmussen, E. Martinez, P. Louka, and D. G. Wingett, "Zinc oxide nanoparticles for selective destruction of tumor cells and potential for drug delivery applications," Expert Opinion on Drug Delivery, vol. 7, no. 9, pp. 1063-1077, 2010.

[207] A. Azam, O. Ahmed, H. Oves, A. Khan, and A. Memic, "Antimicrobial activity of metal oxide nanoparticles against Gram-positive and Gram-negative bacteria: a comparative study," International Journal of Nanomedicine, vol. 7, pp. 6003-6009, 2012.

[208] P. J. P. Espitia, N. D. F. F. Soares, J. S. d. R. Coimbra, N. J. de Andrade, R. S. Cruz, and E. A. A. Medeiros, "Zinc oxide nanoparticles: synthesis, antimicrobial activity and food packaging applications," Food and Bioprocess Technology, vol. 5, no. 5, pp. 1447-1464, 2012.

[209] R. Rajendra, C. Balakumar, H. A. M. Ahammed, S. Jayakumar, K. Vaideki, and E. Rajesh, "Use of zinc oxide nano particles for production of antimicrobial textiles," International Journal of Engineering, Science and Technology, vol. 2, pp. 202-208, 2010.

[210] M. M. AbdElhady, "Preparation and characterization of chitosan/zinc oxide nanoparticles for imparting antimicrobial and UV protection to cotton fabric," International Journal of Carbohydrate Chemistry, vol. 2012, Article ID 840591, 6 pages, 2012.

[211] N. Bellotti, R. Romagnoli, C. Quintero, C. DomínguezWong, F. Ruiz, and C. Deyá, "Nanoparticles as antifungal additives for indoor water borne paints," Progress in Organic Coatings, vol. 86, pp. 33-40, 2015.

[212] C. von Roemeling, W. Jiang, C. K. Chan, I. L. Weissman, and B. Y.S. Kim, "Breaking down the barriers to precision cancer nanomedicine," Trends in Biotechnology, vol. 35, no. 2, pp. 159-171, 2017.

[213] H. Hong, J. Shi, Y. Yang et al., "Cancer-targeted optical imaging with fluorescent zinc oxide nanowires," Nano Letters, vol. 11, no. 9, pp. 3744-3750, 2011.

[214] Y.-W. Huang, C.-H. Wu, and R. S. Aronstam, "Toxicity of transition metal oxide nanoparticles: recent insights from in vitro studies," Materials, vol. 3, no. 10, pp. 4842-4859, 2010.

[215] Y.-Y. Kao, Y.-C. Chen, T.-J. Cheng, Y.-M. Chiung, and P.-S. Liu, "Zinc oxide nanoparticles interfere with zinc ion homeostasis to cause cytotoxicity," Toxicological Sciences, vol. 125, no. 2, pp. 462-472, 2012. 
[216] B. C. Heng, X. Zhao, E. C. Tan et al., "Evaluation of the cytotoxic and inflammatory potential of differentially shaped zinc oxide nanoparticles," Archives of Toxicology, vol. 85, no. 12, pp. 1517-1528, 2011.

[217] V. Valdiglesias, C. Costa, G. Kiliç et al., "Neuronal cytotoxicity and genotoxicity induced by zinc oxide nanoparticles," Environment International, vol. 55, pp. 92-100, 2013.

[218] D. Guo, H. Bi, B. Liu, Q. Wu, D. Wang, and Y. Cui, "Reactive oxygen species-induced cytotoxic effects of zinc oxide nanoparticles in rat retinal ganglion cells," Toxicology in Vitro, vol. 27, no. 2, pp. 731-738, 2013.

[219] V. Sharma, R. K. Shukla, N. Saxena, D. Parmar, M. Das, and A. Dhawan, "DNA damaging potential of zinc oxide nanoparticles in human epidermal cells," Toxicology Letters, vol. 185 , no. 3, pp. 211-218, 2009.

[220] S. Hackenberg, A. Scherzed, A. Technau et al., "Cytotoxic, genotoxic and pro-inflammatory effects of zinc oxide nanoparticles in human nasal mucosa cells in vitro," Toxicology in Vitro, vol. 25, no. 3, pp. 657-663, 2011.

[221] R. Roy, A. Tripathi, M. Das, and P. Dwivedi, "Cytotoxicity and uptake of zinc oxide nanoparticles leading to enhanced inflammatory cytokines levels in murine macrophages: comparison with bulk zinc oxide," Journal of Biomedical Nanotechnology, vol. 7, no. 1, pp. 110-111, 2011.

[222] B. C. Heng, X. Zhao, S. Xiong, K. Woei Ng, F. Yin-Chiang Boey, and J. Say-Chye Loo, "Toxicity of zinc oxide ( $\mathrm{ZnO})$ nanoparticles on human bronchial epithelial cells (BEAS-2B) is accentuated by oxidative stress," Food and Chemical Toxicology, vol. 48, no. 6, pp. 1762-1766, 2010.

[223] C. T. Ng, L. Q. Yong, M. P. Hande et al., "Zinc oxide nanoparticles exhibit cytotoxicity and genotoxicity through oxidative stress responses in human lung fibroblasts and Drosophila melanogaster," International Journal of Nanomedicine, vol. 12, pp. 1621-1637, 2017.

[224] R. Pati, I. Das, R. K. Mehta, R. Sahu, and A. Sonawane, "Zincoxide nanoparticles exhibit genotoxic, clastogenic, cytotoxic and actin depolymerization effects by inducing oxidative stress responses in macrophages and adult mice," Toxicological Sciences, vol. 150, no. 2, pp. 454-472, 2016.

[225] A. M. Abdelmonem, B. Pelaz, K. Kantner, N. C. Bigall, P. del Pino, and W. J. Parak, "Charge and agglomeration dependent in vitro uptake and cytotoxicity of zinc oxide nanoparticles," Journal of Inorganic Biochemistry, vol. 153, pp. 334-338, 2015.

[226] A. K. Gupta, R. R. Naregalkar, V. D. Vaidya, and M. Gupta, "Recent advances on surface engineering of magnetic iron oxide nanoparticles and their biomedical applications," Nanomedicine, vol. 2, no. 1, pp. 23-39, 2007.

[227] S. Laurent, S. Dutz, U. O. Häfeli, and M. Mahmoudi, "Magnetic fluid hyperthermia: focus on superparamagnetic iron oxide nanoparticles," Advances in Colloid and Interface Science, vol. 166, no. 1-2, pp. 8-23, 2011.

[228] N. Tran, A. Mir, D. Mallik, A. Sinha, and S. Nayar, "Bactericidal effect of iron oxide nanoparticles on Staphylococcus aureus," International Journal of Nanomedicine, vol. 5, p. $277,2010$.

[229] G. Nangmenyi, X. Li, S. Mehrabi, E. Mintz, and J. Economy, "Silver-modified iron oxide nanoparticle impregnated fiberglass for disinfection of bacteria and viruses in water," Materials Letters, vol. 65, pp. 1191-1193, 2011.

[230] I. Anghel, A. Grumezescu, A. Holban, A. Ficai, A. Anghel, and M. Chifiriuc, "Biohybrid nanostructured iron oxide nanoparticles and Satureja hortensis to prevent fungal biofilm development," International Journal of Molecular Sciences, vol. 14, pp. 18110-18123, 2013.

[231] C. Lei, L. Zhang, K. Yang, L. Zhu, and D. Lin, "Toxicity of iron-based nanoparticles to green algae: effects of particle size, crystal phase, oxidation state and environmental aging," Environmental Pollution, vol. 218, pp. 505-512, 2016.

[232] V. T. Trang, L. T. Tam, N. Van Quy et al., "Functional iron oxide-silver hetero-nanocomposites: controlled synthesis and antibacterial activity," Journal of Electronic Materials, vol. 46, pp. 3381-3389, 2017.

[233] N. Singh, G. J. S. Jenkins, R. Asadi, and S. H. Doak, "Potential toxicity of superparamagnetic iron oxide nanoparticles (SPION)," Nano Reviews, vol. 1, p. 5358, 2010.

[234] S. J. H. Soenen, U. Himmelreich, N. Nuytten, and M. De Cuyper, "Cytotoxic effects of iron oxide nanoparticles and implications for safety in cell labelling," Biomaterials, vol. 32, pp. 195-205, 2011.

[235] A. Petri-Fink, B. Steitz, A. Finka, J. Salaklang, and H. Hofmann, "Effect of cell media on polymer coated superparamagnetic iron oxide nanoparticles (SPIONs): colloidal stability, cytotoxicity, and cellular uptake studies," European Journal of Pharmaceutics and Biopharmaceutics, vol. 68, pp. 129-137, 2008.

[236] V. Valdiglesias, G. Kiliç, C. Costa et al., "Effects of iron oxide nanoparticles: cytotoxicity, genotoxicity, developmental toxicity, and neurotoxicity," Environmental and Molecular Mutagenesis, vol. 56, pp. 125-148, 2015.

[237] Z. Magdolenova, M. Drlickova, K. Henjum et al., "Coatingdependent induction of cytotoxicity and genotoxicity of iron oxide nanoparticles," Nanotoxicology, vol. 9, pp. 44-56, 2013.

[238] A. Sobhani, A. Manjavacas, Y. Cao et al., "Pronounced linewidth narrowing of an aluminum nanoparticle Plasmon resonance by interaction with an aluminum metallic film," Nano Letters, vol. 15, pp. 6946-6951, 2015.

[239] M. Aramesh, P. A. Tran, K. Ostrikov, and S. Prawer, "Conformal nanocarbon coating of alumina nanocrystals for biosensing and bioimaging," Carbon, vol. 122, pp. 422-427, 2017.

[240] A. Mukherjee, I. Mohammed-Sadiq, T. C. Prathna, and N. Chandrasekaran, "Antimicrobial activity of aluminium oxide nanoparticles for potential clinical applications," in Science against Microbial Pathogens: Communicating Current Research and Technological Advances, A. Méndez-Vilas, Ed., pp. 245-251, Formatex Research Center, Badajoz, Spain, 2011.

[241] Y. C. Rajan, B. S. Inbaraj, and B. H. Chen, "Synthesis and characterization of $\operatorname{poly}(\gamma$-glutamic acid)-based alumina nanoparticles with their protein adsorption efficiency and cytotoxicity towards human prostate cancer cells," RSC Advances, vol. 5, pp. 15126-15139, 2015.

[242] S. Pakrashi, S. Dalai, P. T. C. Prathna et al., "Cytotoxicity of aluminium oxide nanoparticles towards fresh water algal isolate at low exposure concentrations," Aquatic Toxicology, vol. 132-133, pp. 34-45, 2013.

[243] E. Radziun, J. Dudkiewicz Wilczyńska, I. Książek et al., "Assessment of the cytotoxicity of aluminium oxide nanoparticles on selected mammalian cells," Toxicology in Vitro, vol. 25, pp. 1694-1700, 2011.

[244] D. Yoon, D. Woo, J. H. Kim et al., "Agglomeration, sedimentation, and cellular toxicity of alumina nanoparticles in cell culture medium," Journal of Nanoparticle Research, vol. 13, pp. 2543-2551, 2010.

[245] W. Lin, I. Stayton, Y.-W. Huang, X.-D. Zhou, and Y. Ma, "Cytotoxicity and cell membrane depolarization induced by 
aluminum oxide nanoparticles in human lung epithelial cells A549," Toxicological \& Environmental Chemistry, vol. 90, pp. 983-996, 2008.

[246] Y. S. Kim, J. S. Kim, H. S. Cho et al., “Twenty-eight-day oral toxicity, genotoxicity, and gender-related tissue distribution of silver nanoparticles in Sprague-Dawley rats," Inhalation Toxicology, vol. 20, pp. 575-583, 2008.

[247] M. P. More, P. R. Ganguly, A. P. Pandey et al., "Development of surface engineered mesoporous alumina nanoparticles: drug release aspects and cytotoxicity assessment," IET Nanobiotechnology, vol. 11, pp. 661-668, 2017.

[248] J. P. Gibbons, M. P. Monopoli, M. Lundqvist et al., "Human plasma protein adsorption onto alumina nanoparticles relevant to orthopedic wear," Journal of Applied Biomaterials \& Functional Materials, vol. 13, pp. 145-155, 2015.

[249] S. Rajiv, J. Jerobin, V. Saranya et al., "Comparative cytotoxicity and genotoxicity of cobalt (II, III) oxide, iron (III) oxide, silicon dioxide, and aluminum oxide nanoparticles on human lymphocytes in vitro," Human \& Experimental Toxicology, vol. 35, pp. 170-183, 2015.

[250] M. Asztemborska, "Alumina nanoparticles and plants: environmental transformation, bioaccumulation, and phytotoxicity," in Phytotoxicity of Nanoparticles, M. Faisal, Q. Saquib, A. Alatar, and A. Al-Khedhairy, Eds., pp. 335-345, Springer, Cham, Switzerland, 2018. 